\title{
فاعلية برنامج التدريب علي المهارات الاجتماعية في رفع جودة الحياة لاي عينة من طالبات كلية التربية جامعة الباحة
}

\author{
إعداد \\ أ.م / فاطمة محمد أحمد بريك المبك

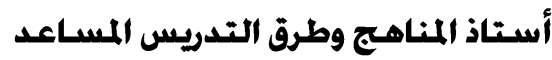

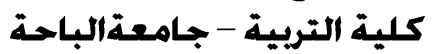 \\ وكبلة عمادة شؤون الطالبات - جامعة الباحة
}

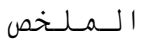

استهلفت الدراسة الحالية النحقق من فاعلية برنامج التنريب علي المهارات الاجتماعية في

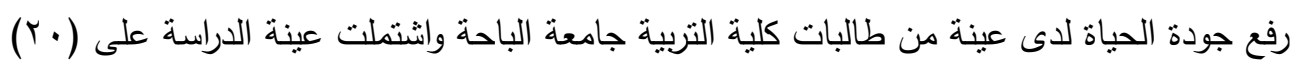
من طلاب كلية التربية تم تقسيمه إلى مجموعتين: مجموعة تجريبية ومجموعة ضابطة قالئة قوام كل مجموعة (• () من طالبات كلية التربية جامعة الباحة وقد استخدت الباحثية الأدوات التالية:

$$
\begin{aligned}
& \text { ا - مقياس جودة الحياة اعداد / د شيماء السعيد الشهاوي. } \\
& \text { r- برنامج التدريب علي المهارات الاجتماعية اعداد / الباحثة. } \\
& \text { وأسفرت الدراسة نتائج على: - ملى }
\end{aligned}
$$

1- توجد فروق ذات دلالة إحصائية في متغير جودة الحياة بين متوسطي رتب درجات طلاب

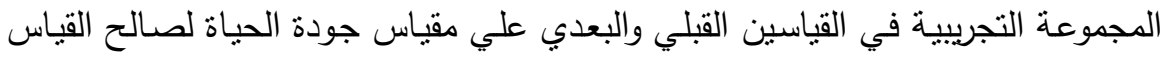

$$
\text { البعدي. }
$$

r- توجد فروق ذات دلالة إحصائية بين متوسطي رتب درجات طلاب المجموعة التجرييية

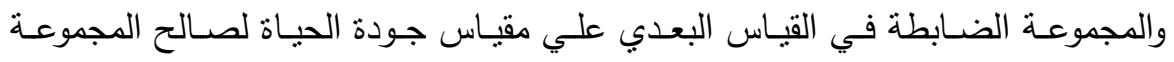

$$
\text { التجريبية. }
$$

r- لا توجد فروق ذات دلالة إحصائية بين متوسطي رتب درجات طلاب المجموعة التجريبية

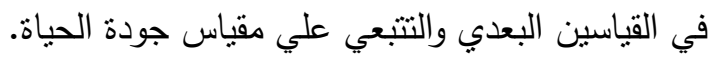




\section{مقدمة البحث}

إن جودة الحياة مفهوم متعدد الأبعاد ونسبي يختلف من شخصل آخر من الناحيتين

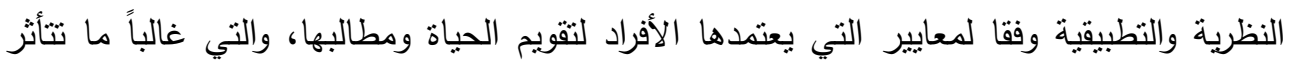

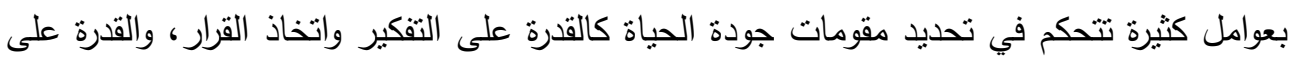
التحكم، وإدارة الظروف المحيطة، والصحة الجسمية والنفسية والظروف الاقتصادية، والمعتقدات

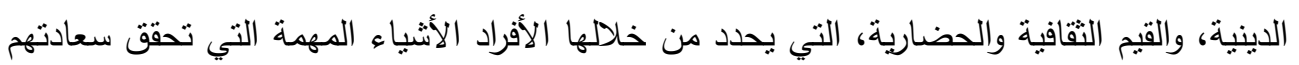
في الحياة.

وتعتبر دراسة جودة الحياة من الدراسات الحديثة نسبياً ، جودة الحياة لها ارتباط وثثق بكل

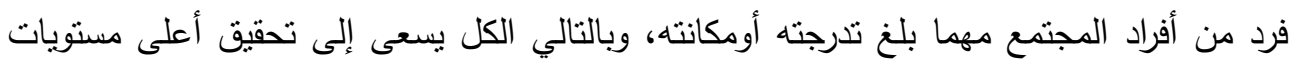

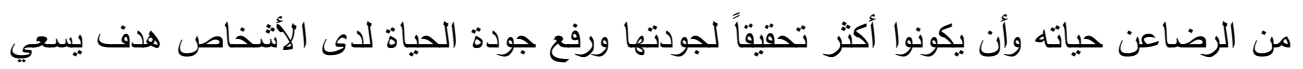
كل فرد إلي تحقيقه في الحياة فيظل الظروف المتلاحقة والسريعة لتحقيق التوافق النفسي والاجتماعي وتحقيق صحة نفسية أفضل .

(Katschnig , 2007, 23 )

والتدريب علي المهارات الاجتماعية يعتمد علي ملاحظة سلوك الآخرين ممن ينسمون

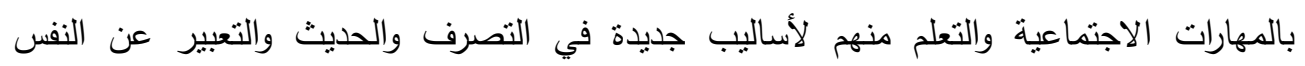

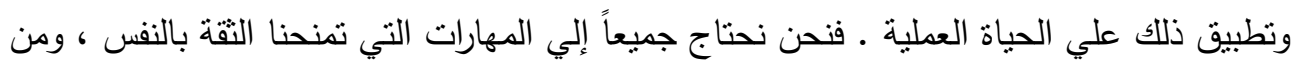

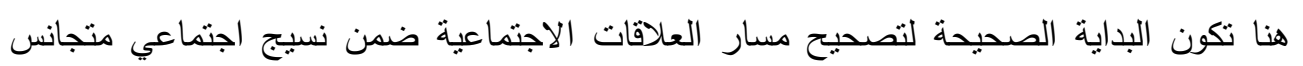

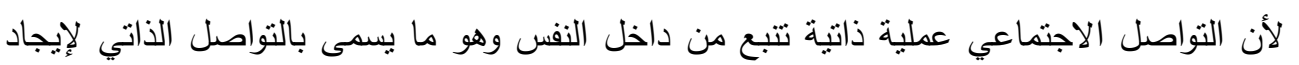

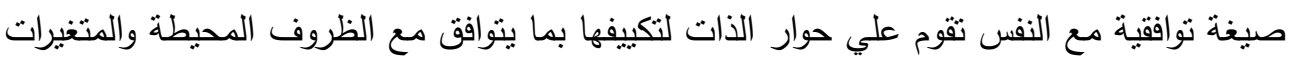
المتلاحقة لتحقيق التواصل الاجتماعي الناجح الذي يمثل الأساس في العلاقات الاجتماعية . ويهدف التدريب على المهارات الاجتماعية إلي زيادة كفاءة أداء الفرد في المواقف الاجنماعية ، والتي تتطلب تفاعلات بين شخصية ، وأنه بواسطة هذا الأداء الفعال يتمكن الفرد من

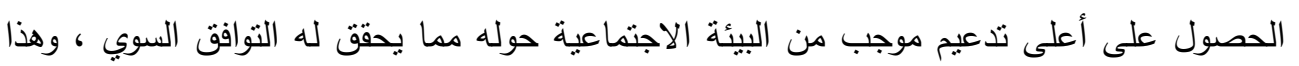
يتطلب بدوره قدراً مقبولاً من المهارات الاجتماعية الأساسية التي تجعلهم يتواصلون بطريقة إيجابية

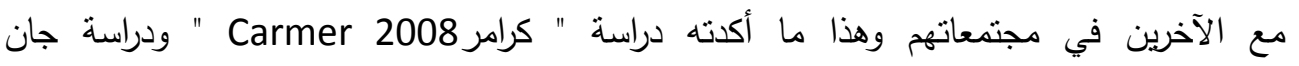

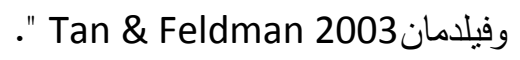

وطالبات الجامعة يمثلن شريحة مهمة في أي مجتمع، حيث أن مرحلة التعليم الجامعي من

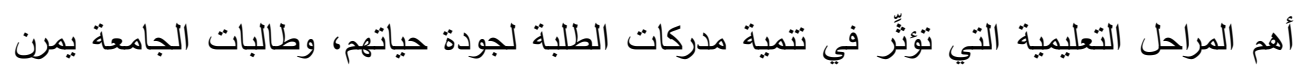
بمرحلة نمائية مهمة في حياتهم، حيث تستعدات للالتحاق بالمهن المختلفة، والزواج والاستقرار

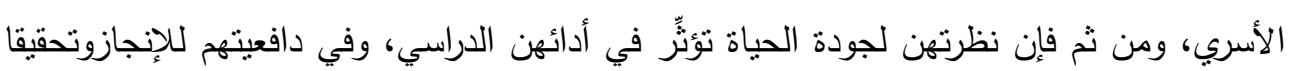

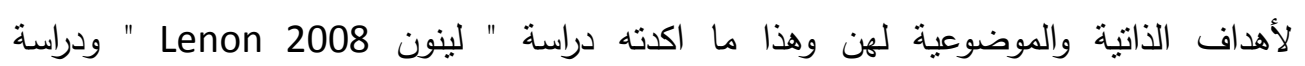
ارنولد2008 Arnold "،وبناء على ذلك فإن محاولة فهم تقدير الطالبات لجودة الحياة وإدراكهن لهاتية 
يعد خطوة مهمة في سبيل فهم هذه المرحلة ومنطلباتها، لذلك تحاول الدراسة الحالية معرفة مدي

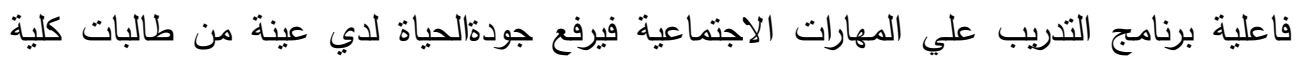
التربية بجامعة الباحة .

\section{مشكلة البحث :}

تتمثل مشكلة البحث في الإجابة علي التساؤلات التالية :

ا- هل توجد فروق ذات دلالة إحصائية في متغير جودة الحياة بين متوسطي رتب درجات

طلاب المجموعة التجريبية في القياسين القبلي والبعدي علي مقياس جودة دودة الحياة لصالح

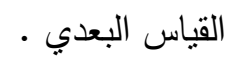

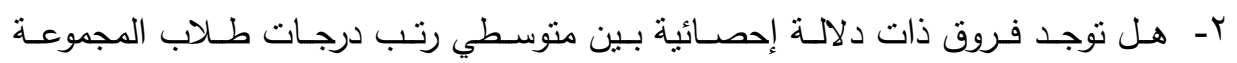

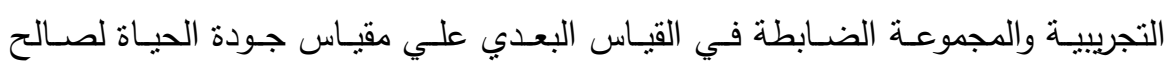

المجموعة التجريبية.

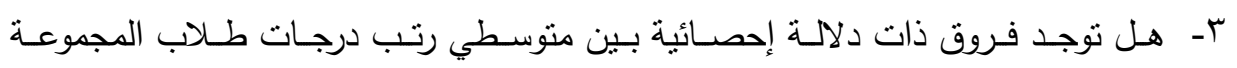

التجريبية في القياسين البعدي والتتبعي علي مقياس جودة الحياة ـ

أهداف البحث : n

ا- الكثف عن الفروق لمتغير جودة الحياة بين منوسطي رتب درجات طلاب المجموعة

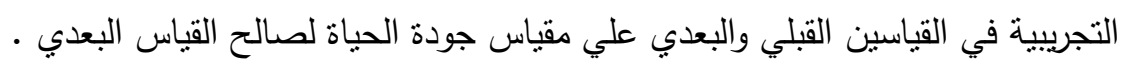

r- الكثف عن الفروق بين متوسطي رتب درجات طلاب المجموعة التجريبية والمجموعة

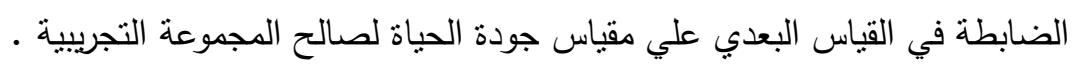

r- الكثف عن الفروق بين متوسطي رثب درجات طلاب المجموعة التجريبية في القياسين

البعدي والتتبعي علي مقياس جودة الحياة .

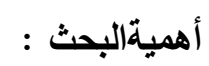

تتضح أهمية دراسةجودة الحياة لدى طلبة الجامعة في النقاط الآتية:

1- إن معرفة مقومات جودة الحياة لدى طالبات الجامعة مما يساعد في الوقوف على مستوى

جودة الحياة لدى فئة عمرية مهمة هن طالبات الجامعة.

r- تعكس جودة الحياة لدى طالبات الجامعات حالتهم الصحية النفسية والجسمية.

r- تتبع أهمية الدراسة من أهية بالتدخل العلاجي ببرنامج يتعدي الجانب الوصفي إلى على

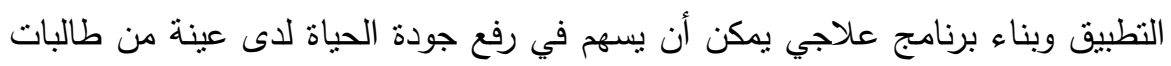


عـ الاهمام بتصميم البرامج للتدريب على المهارات الاجتماعية لأهميتها في صقل وتخريج طلبةذوي كفاعة مميزة اجتماعية وذاتية.

๑ـ - تكنسب هذه الدارسة أهميتها من المفاهيم التي تتناولها، إذ يعد مفهوم جودة الحياة من المفاهيم ذات الأولوية التي تلاقي اهتماما متزايداً سواءعلى المستوى النظري أوالتطبيقي.

\section{مصطلحات البحث}

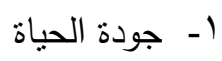

الإدراكات الحسية للفرد تجاه مكانته في الحياة من الناحية الثقافية، ومن منظومة القيم في المجتمع الذي يعيش فيها الفرد، وكذلك علاقته بأهداف هو نوقعاته وثوابته ومعتقداته، وتتثمل أوجها لحالة النفسية ومستوى الاستقلال الثخصي، وتقاس بالدرجة التي تحصل عليها الطالبة علي مقياس جودة الحياة. (شيماء السعبد الثهاوي ، د. ت : ( )

\section{تعرفها الباحثة إجرائياً على أنها :}

تعرف جودة الحياة علي أنها هي إحساس الأفراد والرضا في ضوء ظروف الحياة الحالية، وأنها تتأثز بأحداث الحياة والعلاج أوتغير حدة الوجدان والمشاعر وأن الارتباط بين تقييم جودة الحياة الموضوعية والذاتية يتأثران باستبصار الفرد .

$$
\begin{aligned}
& \text { r- المهارات الاجتماعبة } \\
& \text { تعرفها الباحثة إجرائياً على أنها }
\end{aligned}
$$

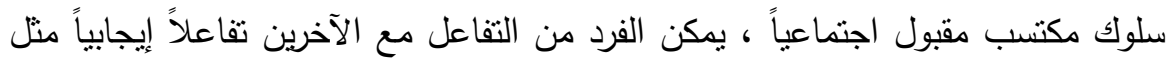
"كسب الأصدقاء ، والتأثير في الآخرين ، والتفاهم والتعاون معهم ، وحل المشكلات الاجتماعية

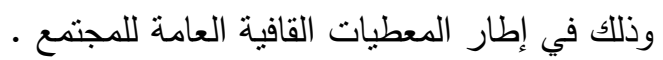

$$
\begin{aligned}
& \text { r- - برنامج التدريب علي المهارات الاجتماعية } \\
& \text { تعرفه الباحثة إجرائياً على أنها : }
\end{aligned}
$$

أنه برنامج يشنمل علي عدد واسع من الإجراءات والأساليب التي تهذف إلي مساعدة

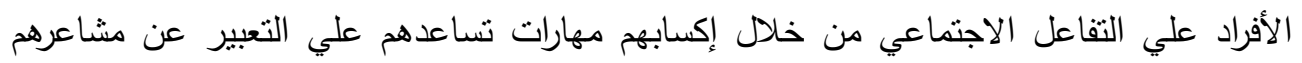
الإيجابية والسلبية ، والضبط الاجنماعي والإنفعالي أثناء المواقف الاجتماعية ، والحساسية لأثكال الإتصال اللفظي وغير اللفظي ، وقواعد السلوك الاجتماعي والتعبير عن الأفكار أمام الآخرين والحوار معهم ، وذللك لتحقيق التواصل الاجتماعي مع الآخرين دون الإحساس بالخوف وأو أو الخجل

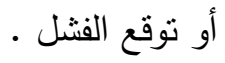


الإطار النظري

المحور الأول : جودة الحياة

زاد اهتمام الباحثثن بمفهوم جودة الحياة منذ بداية النصف الثاني للقرن العشرين كمفهوم

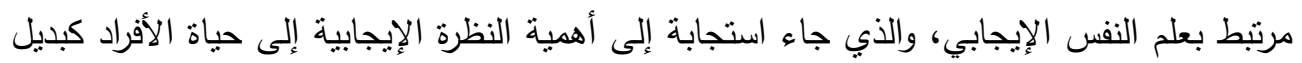
للتركيز الكبير الذي أولاه علماء النفس للجوانب السلبية من حياة الأفراد، وقد تعددت قضايطائ البحث

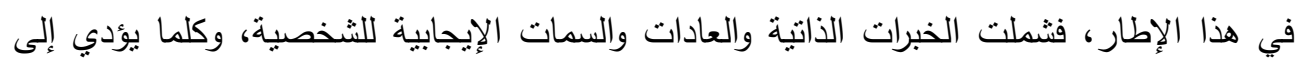
تحسين جودة الحياة، وقد أكدت دراسات القرن الماضي أن الجانب الإيجابي فيشخصية الإنسان هو الإنية

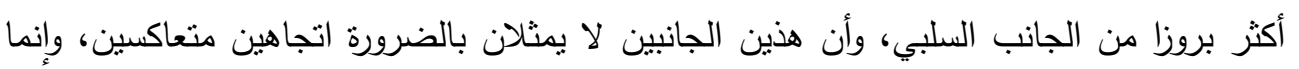

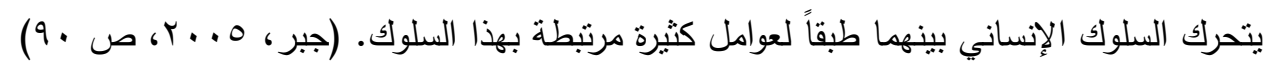

\section{مفهوم جودة الحياة}

وعلى الرغم من عدم الاتفاق على تعريف واحد لمفهوم جودة الحياة، إلا أنه عادة ما يشار

فيأدبيات المجال إلى تعريف منظمة الصحة العالمية بوصفه أقرب التعريفات إلى توضيح

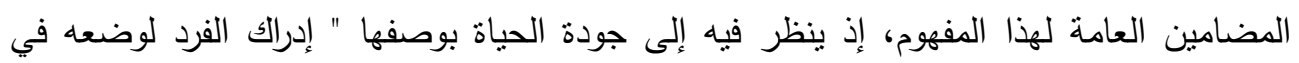
الحياة في سياق الثقافة وأنساق القيم التي يعيش فيها ومدى تطابق أوعدم نطابق ذلك مع إنى أهدافه،

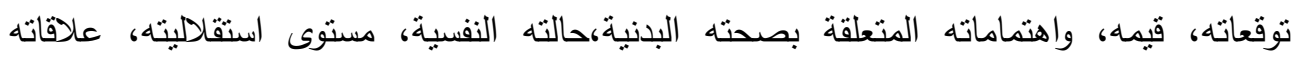

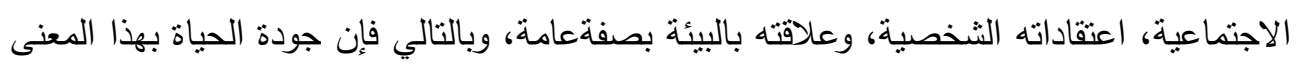
تنشير إلى تقييمات الفرد الذاتية لظروف حياته" (Whoqol, 2005, p12) وتعرف جودة الحباة علي أنها الاستمتاع بالظروف المادية في البيئة الخارجية والإحساس بحسن الحال، وإثباع الحاجات، والرضا عن الحياة، وإدرالك الفرد لقوى ومضامين حياته وشعوره بمعنى الحياة إلى جانب الصحة الجسمية الايجابية وإحساسه بالسعادة وصولا إلى عيش ولى حياة

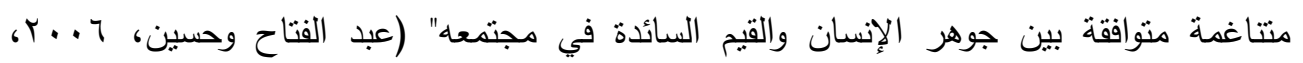
ص ص

وهي درجة إحساس الفرد بالتحسن المستمر لجوانب شخصيته في النواحي النفسية، والمعرفية، والإبداعية، والثقافية، والرياضية، والثخصية، والجسمية، والتتسيق بينها، مع تهيئة المناخ بان

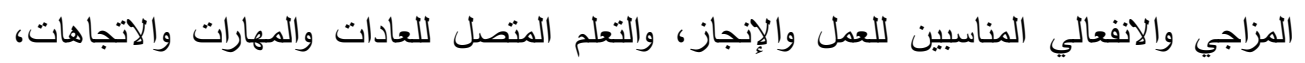
وكذللك تعلم حل المشكلات وأساليب التوافق والتكيف، وتنبي منظور التحسن المستمر للأداء كأسلوب حياة، وتلبية الفرد لاحتباجاته ورغباته بالقدر المتوازن، واستمرارية في توليد الأفكار

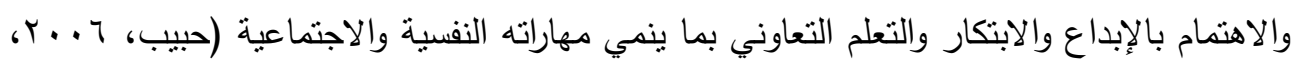




\section{أبعاد جودة الحياة}

مفهوم جودة الحياة مفهوماً متعدد الأبعاد يتضمن أربعة أبعاد هي "الكفاءة السلوكية، ضبط

البيئة أوالسيطرة عليها، جودة الحياة المدركة، وجودة الحياة النفسية (Lawton,1991,P.35).

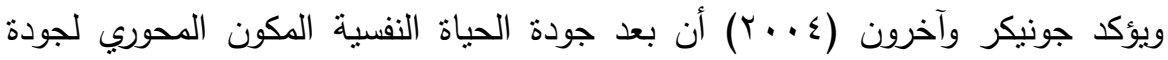

الحياة بصفة عامة، ويعرف ان جودة الحياة النفسية على وجها لتحديد بأنها بالإضافة إلى تحرر

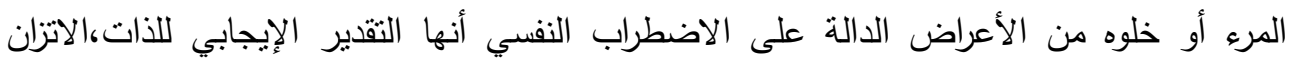
الانفعالي،الإقبال على الحياة،وتقبل الآخرين (Jonker,etal.,2004,PP. 159-164).

تتمنتل مقومات جودة الحباة في حالة المعافاة الكاملة بدنياً وعقلياً ونفسياً واجتماعياً. ووفق تعريف منظمة الصحة العالمية فإن للصحة عناصر عدة هي: • الصحة الجسدية: القدرة على القيام بوظائف الجسم الديناميكية وحالة منلى من اللياقة البدنية.

• الصحة النفسية :القدرة على التعرف على المشاعر والتعبير عنها، وشعور الفرد بالسعادة والراحة النفسية دون اضطراب أو تردد.

• الصحة الروحية : وهي صحة تتعلق بالمعتقدات والممارسات الدينية للحصول على سلام مع النفس. •الصحة العقلية: وهي صحة نتعلق بالقدرة على التفكير بوضوح وتتاسق والثعور بالمسؤولية، وقدرة على حسم الخيارات واتخاذ القرارات وصنعها. الصحة الاجتماعية: وهي القدرة على إقامة العلاقات مع الآخرين والاستمرار بها والاتصال والتواصل مع الآخري نواحترامهم. الصحة المجتمعية: وهي القدرة على إقامة العلاقة مع كلما يحيط بالفرد من مادة وأثخاص وقوانين وأنظمة. ويمكن تمييز ثلاثة أبعاد لجودة الحياة: هودة الحياة الموضوعية: وتتمل هذه الفئة الجوانب الاجتماعية لحياة الأفراد والتي يوفرها المجتمع من مسنلزمات مادية.

جودة الحياةا لذاتية، ويقصدبها مدى الرضا الثخصي بالحياةهشعور الفرد بجودة الحياة. جودة الحياة الوجودية، وتمّنل الحد المثالي لإثباع حاجات الفرد، واستطاعته العيش بتوافق

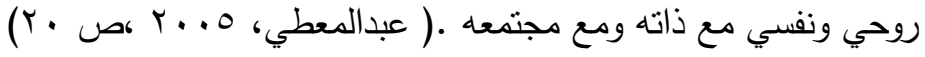

$$
\begin{aligned}
& \text { وتتكون جودة الحياة من ثلاث مكونات رئيسية تتمثل في مايلي:- }
\end{aligned}
$$


• الإحساس الداخلي بحسن الحال والرضا عن الحياة الفعلية التي يعيشها المرء (بينما يرتبط الإحساس بحسن الحال بالانفعالات، يرتبط الرضا بالقناعات الفكرية أوالمعرفية الداعمة

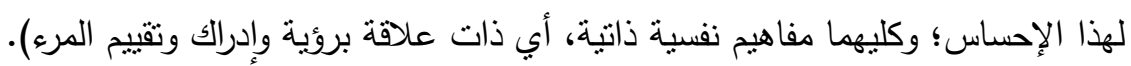
• القدرة على رعاية الذات والالنزام والوفاء بالأدوار الاجتماعية (تمنل الإعاقة المنظور المناقض لهذه القدرة، وترتبط بعجز المرء عن الالتزام أو الوفاء بالأدوار الاجتماعية). • القدرة على الاستفادة من المصادر البيئية المتاحة الاجتماعية منها (المساندة الاجتماعية)، والمادية (معيار الحياة) وتوظيفها بشكل إيجابي.

( Katschnig , 2007, 11)

وطرح(Felce\&Perry ,2007, 15) نموذج ثلاثي العناصر لجودة الحياة يعكس التفاعل

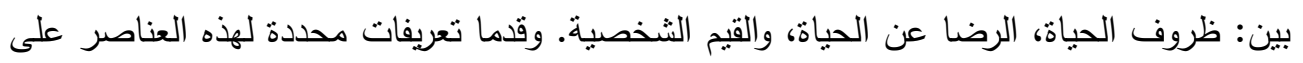

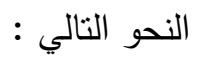

• ظروف الحياة Life conditions : وتتضمن الوصف الموضوعي للأفراد وللظروف المعيشية لهم.

• الرضا الثخصي عن الحياة personal satisfaction: ويتضمن ما يعرف بالإحساس بحسن الحال والرضا عن ظروف الحياة أوأسلوب الحياة.

• القيم الثخصية والطموح الثخصي Personal values and aspiration: تتضمن القيمة أو الأهمية النسبية التي يسقطها الفرد على مختلف ظروف الحياة الموضوعية أوجودة الحياة الذاتية.

Hajiran, : وعلى صعيد الدراسات التي تتاولت مفهوم جودة الحياة، أوضحت دراسة (2006; Picher, 2006

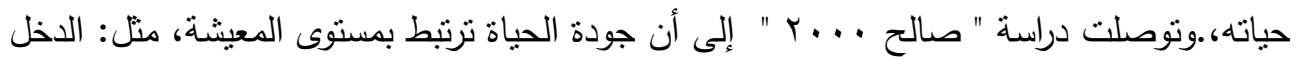

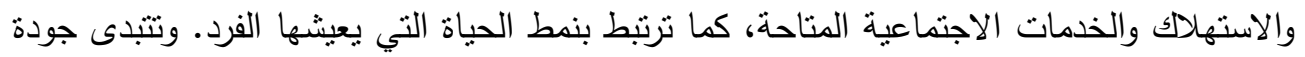

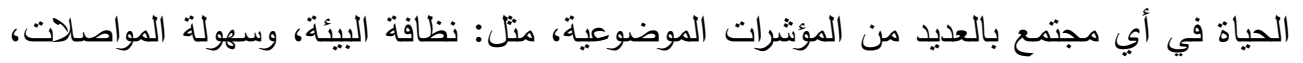
وتوافر السلع، وزيادة الدخل، وتوافر فرص التعليم والعمل، وتوافر الخدمات الصحية المناسبة، وحرية

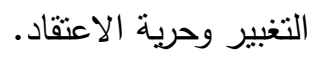

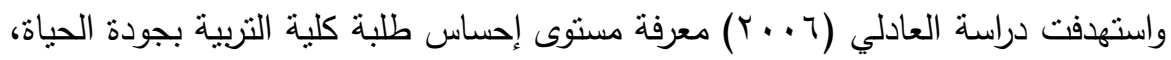
ومعرفة طبيعة الفروق في متغيري الجنس والتخصص الدراسي. كما أظهرت النتائج وجود فروق دالة النها إحصائيا بين الذكور والإناث لصالح الذكور ، ووجود فروق دالة في التخصص الدئيس بالفروق بين متوسط درجات طلبة تخصص الدراسات الاجتماعية ومتوسط درجات طلبة بقية التخصصات المشمولة بالبحث. 
وهدفت دراسة" حسنوأخرين ج · . ب " إلي إظهار مستوى جودة الحياة، الضغوط النفسية، مقاومة الضغوط النفسية لاى طلبة جامعة السلطان قابوس، اختلاف مستويات تلك المتغيرات وفقا لمتغير جنس الطالب ونوع كليته،علاقة كل من جودة الحياة واستراتيجيات مقاومة الضغوط بمستوى الضغوط النفسية لدى طلبة الجامعة، اختلاف تلك العلاقات وققاً لمتغير جنس الطالب ونوع كليته

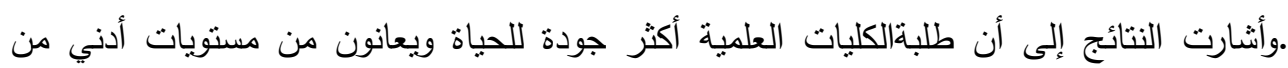

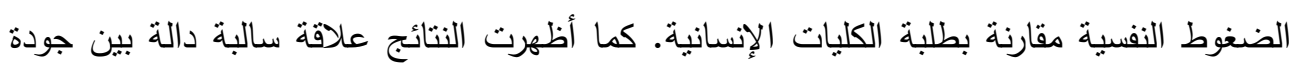

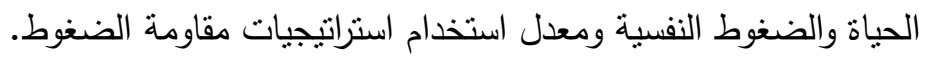

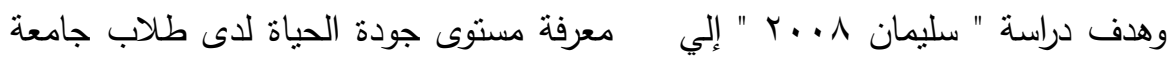
تبوك في ضوء متغير التخصص والتقدير الدراسي للطالب وطبيعة العلاقة بين أبعاد جودة الحياة وكل من دخل الأسرة الثهري ، وتوصلت الدراسة إلي إن مستوى جودة الحياة كان مرتفعاً في بعدين من أبعاد جودة الحياة هم: جودة الحياة الأسرية، وجودة الحياة النفسية، ومنخفض في في بلإل بعدينهما: جودة الحياة التعليمية وجودة إدارة الوقت ومتوسط في بعد جودة الصحة العامة ، ووجود تأثأثير دال إحصائياً في متغير التخصص على جميع أبعاد جودة الحياة باستثناء بعد جودة إدارة الوقت، وكأ ودان التأثير لصالح التخصصات التعي فئي في أبعاد جودة الحياة العامة.

أوضحت دراسة " نعيسه ب ا ـ ب " والتي هدفت إلي التعرف على مستوى جودة الحياة لدى طلبة جامعتي دمشق وتترين حسب متغيرات البلد، النوع، التخصص وتوصلت الدراسة إلى إلي وجود

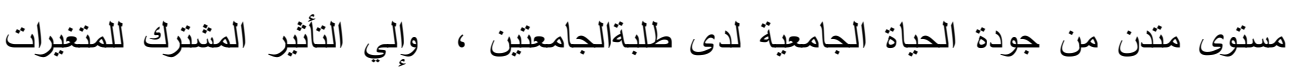

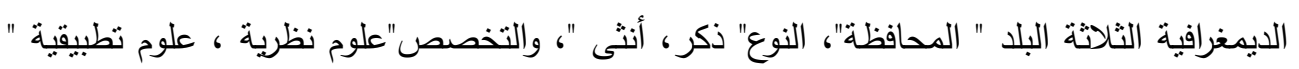

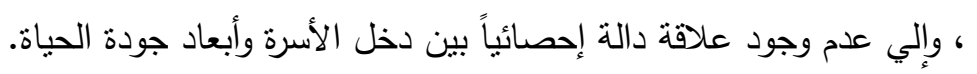
المحور الثاني : التدريب علي المهارات الاجتماعية

لقد تزايد الاهتمام بالمهارات الاجتماعية ودورها في تحقيق التكيف الاجتماعي في العقدين الآخرين حيث تمثل المهارات الاجتماعية أحد المهارات الأساسية والهامة في حياة الفرد وحياة الذيني

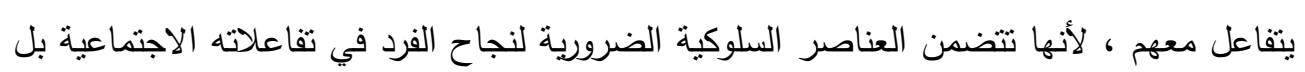

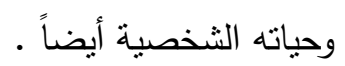

\section{مفهوم التدريب علي المهارات الاجتماعية}

يستعمل التدريب علي المهارات الاجتماعية مع من لديهم ضعف في ثقتهم بأنفسهم ، وفي

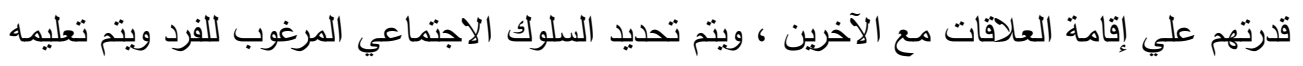

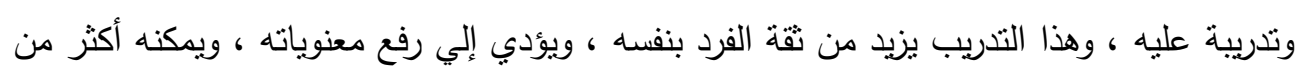

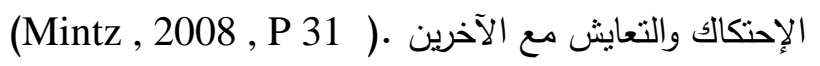

عرف " أبو هاشم ، ع . . r ، VT " التدريب علي المهارات الاجتماعية بأنه أحد الأساليب العلاجية المؤسسة علي التعلم ، وعلي الأخص التعلم بالملاحظة ، ويهذف إلي زيادة كفاءة الأداء 
في المواقف الاجتماعية الحرجة والتي تتطلب تفاعلات بين شخصية ، ويري أنه بواسطة هذا الأداء الفعال يتمكن الفرد من الحصول علي أعلي تدعيم موجب من البيئة الاجتماعية وبواسطته يتلاشي لئي

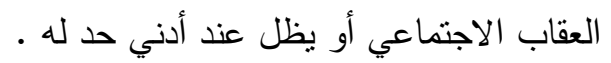

هو نوع من العلاج يقدم للأفراد الذين يحتاجون التغلب علي المعوقات الاجتماعية أو عدم

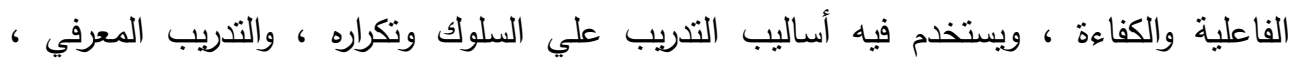
والتدريب علي الثقة بالنفس مع الأشخاص الأسوياء في الأساس الذين يؤدون وظائفهم ، كما يستخدم

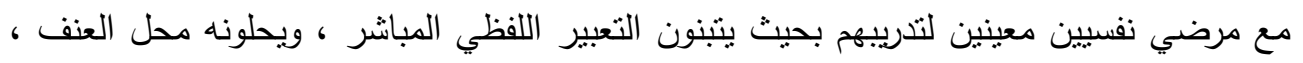

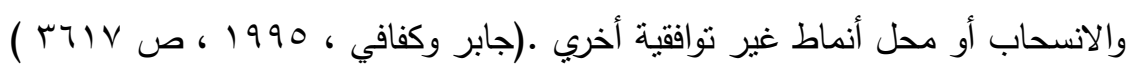
ثانياً : مكونات المهارات الاجتماعية

ويذكر " Hazel " أن المهارات الاجتماعية لطلاب المرحلة الجامعية وما بعدها تتمنل في:

$$
\text { ا - - مهارات اتصال غير لفظية وتتشتمل علي :- }
$$

أـ مهارات التعبير الانفعالي : وتدور حول إرسال الرسائل الانفعالية مع قدرة الفرد

$$
\text { علي التعبير عن مشاعره ، وحالاته الانفعالية . }
$$

بـ الحساسية الانفعالية : وتعكس المهارة في استقبال وتفسير التواصل غير اللفظي

$$
\text { للآخرين مع التهيؤ للاندماج العاطفي معهم - لونعله }
$$

ج- الضبط الانفعالي : ويعني القدرة علي ضبط وتتظيم التعبيرات الانفعالية غير

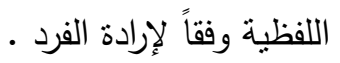

$$
\text { r - مهارات اتصال لفظية أو اجتماعية وتتنتمل علي : }
$$

أـ ـ مهارات التعبير الاجتماعية : وتعني القدرة علي التعبير اللفظي المؤثر في

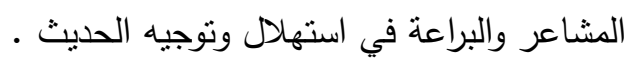

ب- الحساسية الاجتماعية : وهي تعني قدرة الفرد علي إدراك المعايير التي تحكم

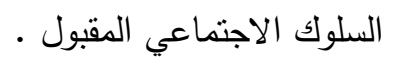

ج- الضبط الاجتماعي : وتعني تقديم الذات للآخرين ، والتصرف بكفاءة عند التفاعل معهم ، والقدرة علي توجيه مسار التواصل .

( Hazel , 2008 , P 40 )

ويشير " بولكليوكارمير Bullkely\&Carmer • (1 ب " إلي أنه يمكن تلخيص أهم

$$
\text { المكونات الأساسية للمهارات الاجنماعية فيما يلي :- }
$$

ا- - يقرر بعض الباحثين أنها مهارات أولية أو أساسية ، متل مهارات الإصغاء والإستماع

$$
\text { والبدء بالحوار والاستمرار فيه وطرح الأسئلة . }
$$


r- يري فريق آخر أنها مهارات اجتماعية متقدمة متل طلب المساعدة والتعامل مع الآخرين ،

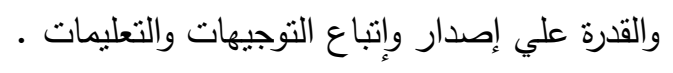

r- بري فريق ثالث أنها مهارات لازمة للتعامل مع الضغوط والإجهاد ومشاعر الفرح والحزن

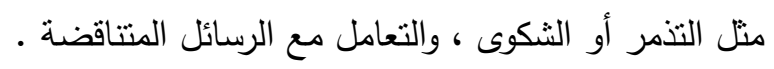

ع- يري فريق رابع أنها مهارات خاصة بالتخطيط في الوقت الحاضر أو من أجل المستقبل

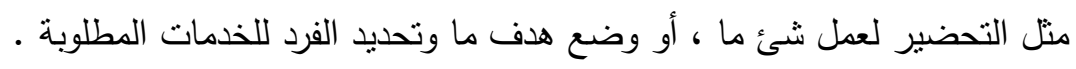

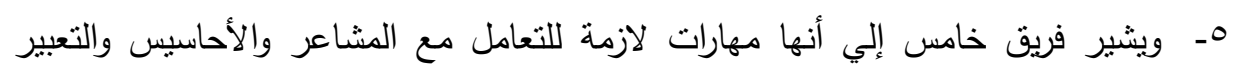

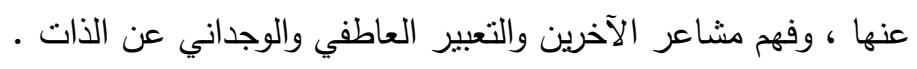

(Bullkely\&Carmer, 2010 , P 225 )

وبعد هذا العرض للآراء والاتجاهات المختلفة التي قدمت للتوصل إلي أهم مكونات

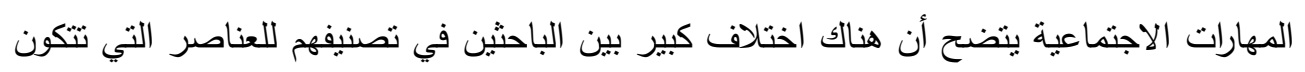

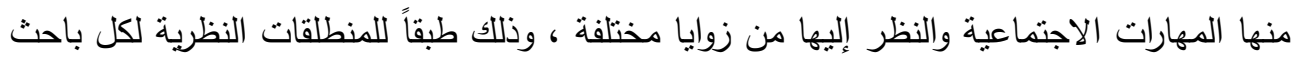
وخلفياته العلمية ، حيث أنثار بعضهم إلي أنها تتقسم إلي جانب انفعالي وجانب النها اجتماعي ، بينما

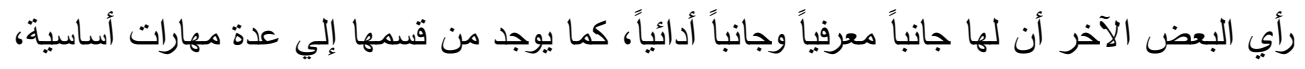

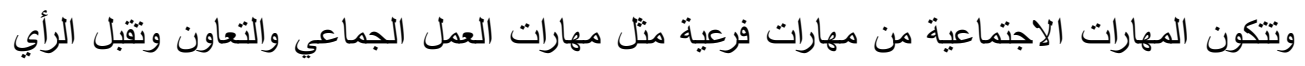
الأخر والمشاركة في المناقتشات والمناظرات وصنع القرارات والصداقة والود والتعاون والقيادة وإثارة

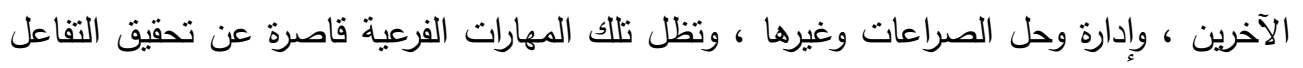
الإيجابي للفرد إذا لم تتكامل مع بعضها إلي الحد الذي يتمكن الفرد من أدائها .

\section{أهمية التدريب علي المهارات الاجتماعية}

تعد المهارات الاجتماعية من أهم المهارات التي ينبغي أن يتعلمها الفرد ليصبح أكثر قبولاً وتكيفاً في

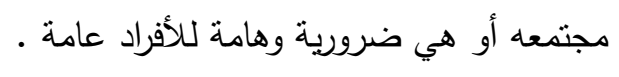

وتتير " هربرت Herbert ^. . ب " إلي أن أهمية التدريب علي المهارات الاجتماعية

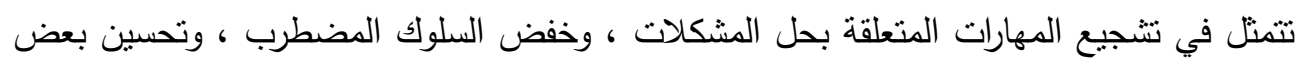

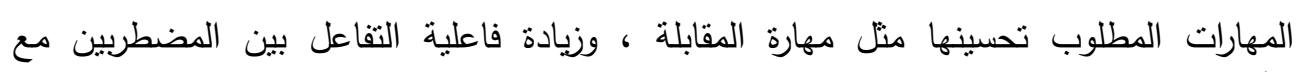

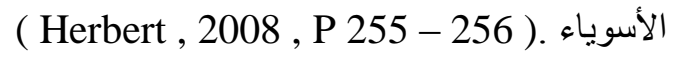

تساهم المهارات الاجتماعية في زيادة ثقة الفرد بنفسه حيث تمكنه من فهم المشكلات

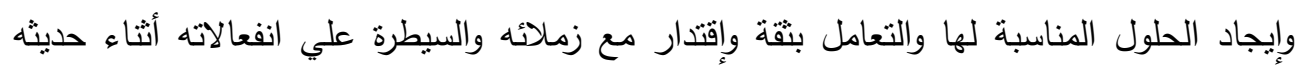

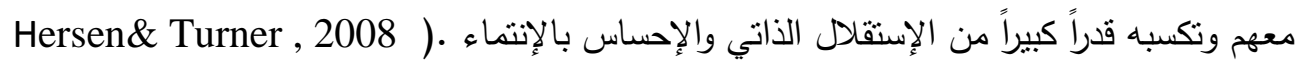


تمكن المهارات الاجتماعية الفرد من إقامة علاقات وثثقة مع المحيطين به والحفاظ عليها

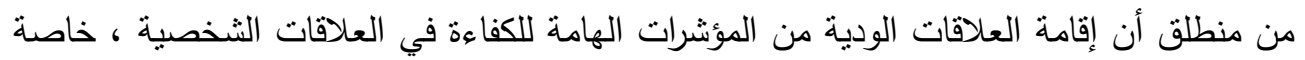
وأن الفرد يحيا في ظل شبكة من العلاقات التي تتضمن الأفراد الآخرين ، ومن ثم فإن نتمية فئن المهارات الاجتماعية ضرورة للشروع في إقامة علاقات شخصية ناجحة ومستمرة . Adkins ) 2008 , P 100 )

يتضح مما سبق مدي أهمية المهارات الاجتماعية فهي نساعد الفرد علي إقامة علاقات

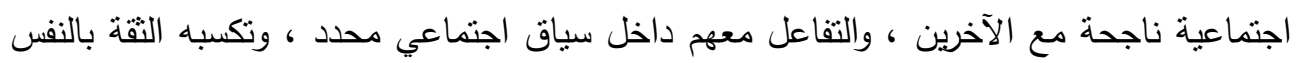

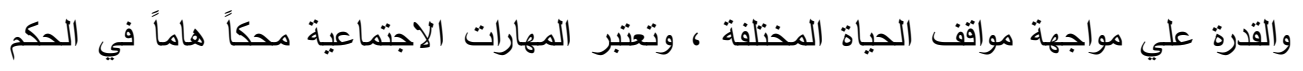
علي السلوك السليم فهي تكتسب أهيتها من أنها نساعد الفرد علي التفاعل مع الآخرين والمحيطين

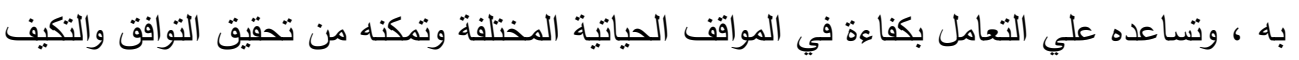
الاجتماعي ، وتتكل المهارات الاجتماعية حاجز يمنع الفرد من الانعزال عن المحيطين به الهاعله والإصابة بالاضطراب النفسي حيث تمكنه من استثمار الفرص المتاحة لإقامة علاقات ودية وثثيقة

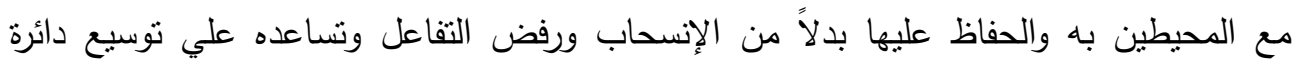

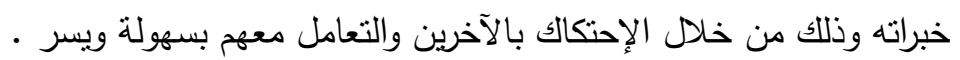

\section{خصائص المهارات الاجتماعية}

تعتبر المهارات الاجتماعية أحد جوانب التعلم الهامة والتي تقوم بدوراً كبيراً في تقوية

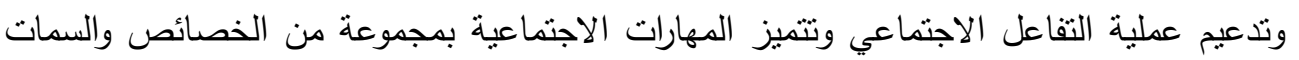
التي تتميز بها عن غيرها وفيما يلي عرض لأهم خصائص المهارات الاجتماعية :

تعتبر المهارات الاجتماعية مهارة مكتسبة وليست موروثة من خلال ملاحظة

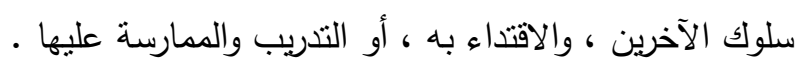

تتطلب المهارات الاجتماعية نوع من التآزر بين المكونات اللفظية وغير

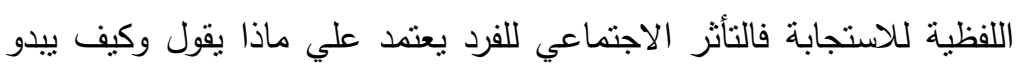
لحظة الكلام

تتطلب المهارات الاجتماعية ثلاثة عناصر أساسية تتمنل في موقف يختلف باختلاف الظروف والسياق ، وفاعلية أو كفاءة التفاعل بين المتعلمين ، ودور الشخص الآخر والقدرة علي إظهار السلوك دون إلحاق الأذي بالآخرين . تتنكل المهارة الاجتماعية بناءاً علي معايير اجتماعية ذاتية صعبة التحديد

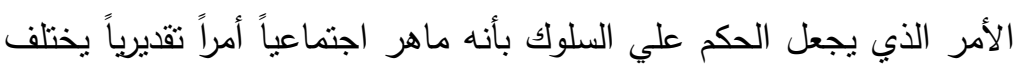

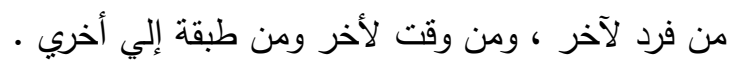
تشتمل المهارات الاجتماعية علي سلوكيات لفظية وغير لفظية . (Wilson, 2007 , P 80 ) 


$$
\text { وهناك عدة خصائص أساسية للمهارات الاجتماعية أهمها ما يلي : }
$$

ا- تنتمل المهارات الاجتماعية علي البراعة والكفاءة والخبرة في أداء الفرد لنشاطاته

$$
\text { الاجتماعية ومختلف أنثكال تقاعلاته مع الآخرين • }
$$

r- العنصر الجوهري في أية مهارة اجتماعية يتمثل في القدرة علي تحقيق نتيجة فعالة في

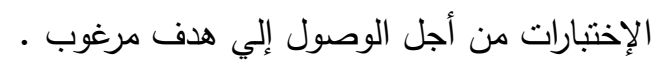

r- تشنتمل المهارات الاجتماعية علي قدرة الفرد علي الضبط المعرفي لسلوكه

عـ - تتحدد المهارات الاجتماعية في ضوء جوانب معينة من سلوك الفرد وخصاله ، وفي إطار

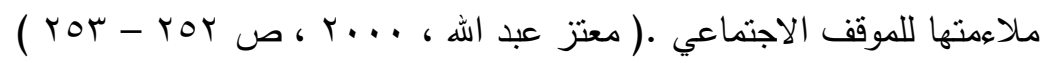

$$
\begin{aligned}
& \text { تصنيف المهارات الاجتماعية }
\end{aligned}
$$

تصنف المهارات الاجتماعية وما تحويه من ذخيرة سلوكية إلي أربع مهارات رئيسية هي :1 - مهارات التواصل والحوار : وهي تلك المهارات التي تتعلق بمعالجة المشكلات الناتجة

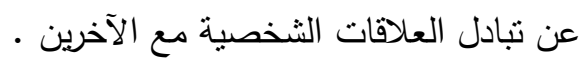

r- مهارات الإصرار أو المهارات التوكيدية : وهي تتعلق بعملية إكساب التعلم للأسلوب

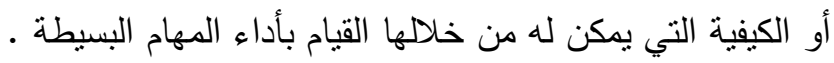

r- مهارات التعبير عن الذات : وهي التي تساعد الكتعلم علي إكساب الطريقة المناسبة

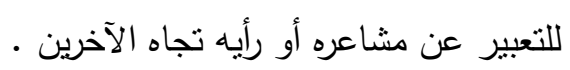

ــ ـ مهارات تعزيز الآخرين : وهي تتعلق بعملية إكساب المتعلم للأسلوب المناسب لكيفية

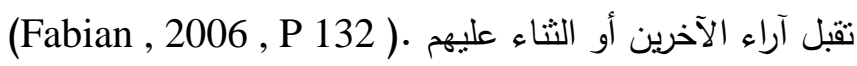

ومما سبق يتضح أنه تتعدد تصنيفات المهارات الاجتماعية ، وغالباً ما يرجع ذلك إلي

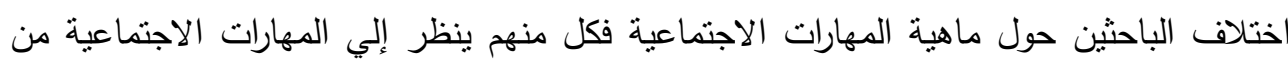
وجهة نظر خاصة في ضوء السلوك الصادر من الفرد ويتضح ذلك الأمر من خلال التصنيفات

$$
\text { المتعددة للمهارات الاجتماعية . }
$$

بري " هنسين ولييرمان Heinssen\&Liberman § ا.ب " في دراسته التي هدفت إلي

دراسة العلاج النشط للتدريب علي المهارات الاجتماعية والسلوك الاجتماعي لمنخفضي جودة الحياة،

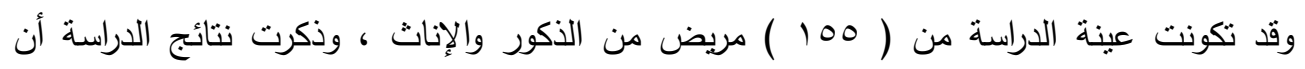

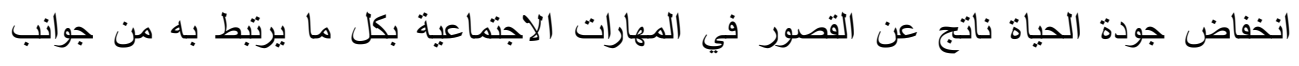

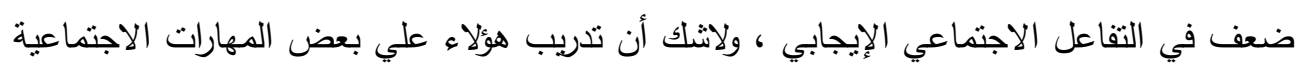
سوف يساعدهم علي استيعاب مشاكلهم وتحقيق التوافق والتكيف لديهم . 
أما عن علاقة التدريب علي المهارات الاجتماعية بجودة الحياة فقد ذكرت نتائج دراسة " فيرز  يؤدي إلي بناء النقة وتعزيز من تقدير الذات .

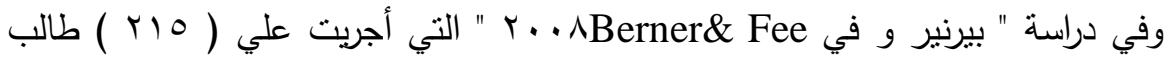
وطالبة من طلاب الجامعة ، وبعد توزيع استماره لتقييم المهارات الاجتماعية لديهم نوصلت نتائج

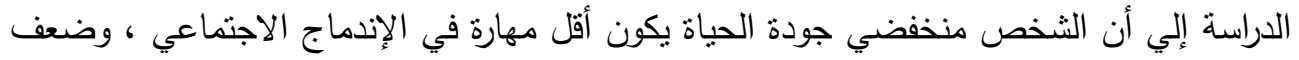
تقدير الذات ، وأوصت الدراسة بأنه يجب إكسابهر بعض المهارات الاجتماعية .

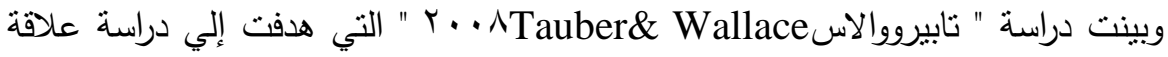
جودة الحياة بنقص المهارات الاجتماعية لعينة تكونت من ( r ) طالب في مرحلة الجامعة،

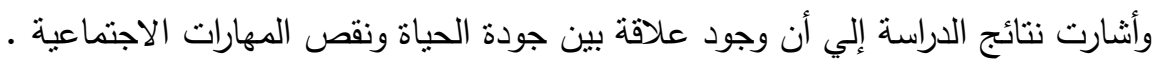

ومن الدراسات السابقة نستخلص أهمية التدريب علي المهارات الاجتماعية لرفع جودة

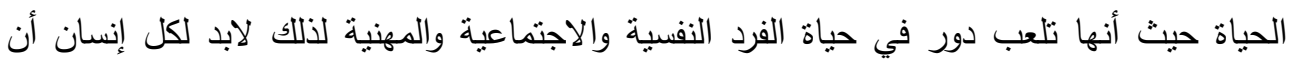

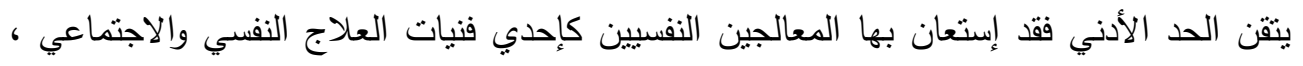
فتتمية المهارات الاجتماعية تساعد الفرد علي إقامة وتدعيم علاقاته بالآخرين ويكون قادر علي الدخول في علاقات سوية مع الآخرين وتساعده علي التفاعل الاجتماعي الإيجابي وتحمل المسئولية ومواجهة المشكلات ومواقف الحياة المختلفة .

\section{فروض الدراسة}

ا- توجد فروق ذات دلالة إحصائية في متغير جودة الحياة بين متوسطي رتب درجات طلاب

المجموعة التجريبية في القياسين القبلي والبعدي علي مقياس جودة الحياة لصالح القياس

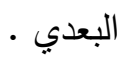

r- توجد فروق ذات دلالة إحصائية بين متوسطي رثب درجات طلاب المجموعة التجريبية والمجموعة الضابطة في القياس البعدي علي مقياس جودة الحياة لصالح المجموعة التجريبية . r- لا توجد فروق ذات دلالة إحصائية بين متوسطي رتب درجات طلاب المجموعة التجريبية في القياسين البعدي والتتبعي علي مقياس جودة الحياة .

تكونت عينة الدراسة من ( • r ) طالبة من طالبات كلية التربية بجامعة الباحة ممن حصلوا علي الدرجات المنخفضة علي مقياس جودة الحياة ، وتم تقسيم الطالبات على أساس التجانس فيما بينه لبنه 
في الصفات التتخيصية إليمجموتنينعد الطالبات في كل منها ( . طلاب ) وهي على النحو

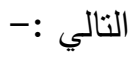
1 - مجموعة ضابطة

لا تتلقي أي برامج وعددها ( • (1) . r- مجموعة تجريبية

تتلقي البرنامج المعرفي السلوكي وعددها (• (1) .

$$
\text { أدوات الدراسة : }
$$

(1) مقياس جودة الحياة إعداد / د شيماء السعيد الشهاوي

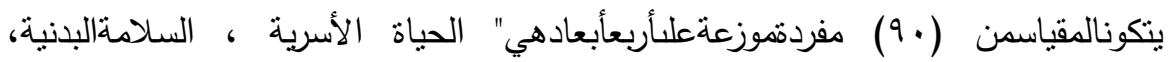

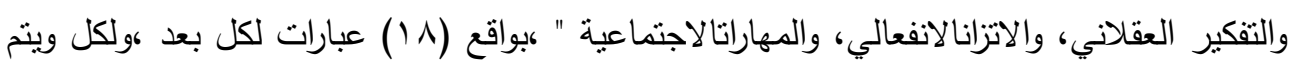

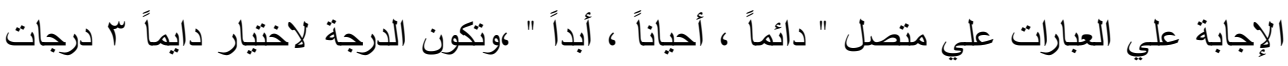

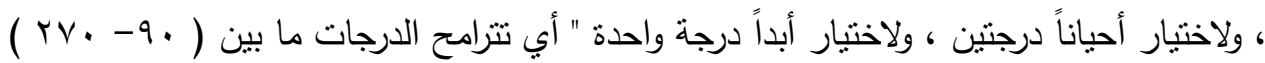

صدق المقياس: اعتمدت الباحثة في تقدير الصدق على:الصدق الاتساق الداخلي : - الصاق

تم حساب معاملات الاتساق الداخلي للمقياس بإيجاد معاملات الارتباط بين أبعاد المقياس الخمسة والدرجة الكلية كما هو موضح في الجدول التالي : 


\section{جدول رقم ( )}

معاملات الارتباط الا|خلية بين الأبعاد الخمسة والارجة الكلية لمقياس جودة الحياة الارجة الكلية البعد الخامس البعد الرابع البعد الثالث البعد الثاني البعد الأول الأبعاد البعد الأول

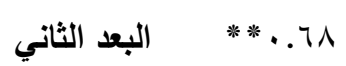

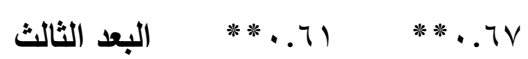

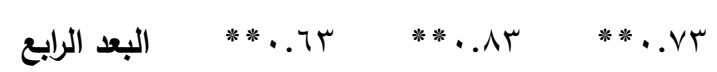

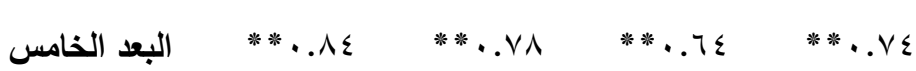

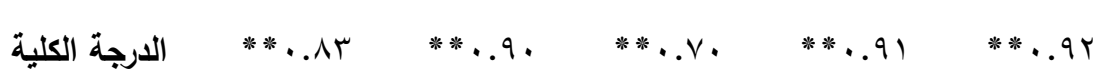

*** دالة عند مستوي I . . .

ثبات المقياس

اعتمدت الباحثة في تقدير الثبات على:-

(أ) طريقة إعادة التطبيق :

حيث طبق المقياس مرنين بفارق زمني أسبوعين بين التطبيقين علي عينة قوامها ( .) من طالبات المستوي الثالث بكلية التربية جامعة الباحة من أقسام مختلفة ، وكان معامل الارتباط بين التطبيقين كالتالي :- n 


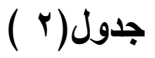

معاملات ثبات المقياس بطريقة ألفا كرونباخ

\begin{tabular}{|c|c|}
\hline الأبعاد & لفاكرونباخ \\
\hline الحياة الأسرية & $* * . .10$ \\
\hline السلامة البانية & $* * . . \wedge 9$ \\
\hline التفكير العقلاني & $* * . . \wedge \varepsilon$ \\
\hline الاتزان الانفعالي & $* * . \wedge v$ \\
\hline المهارات الاجتماع & $* * . . \wedge V$ \\
\hline
\end{tabular}

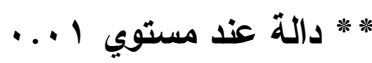

(ب) معادلة تحليل التباين ألفاكرونباخ :

تم حساب الثبات عن طريق معادلة تحليل النباين الفاكرونباخ وقد كانت قيمة ألفا للارجة

$$
\begin{aligned}
& \text { الكلية ( ع^. . ) ) وهي قيمة مرتفعة وتتير إلي ثبات الدقياس . }
\end{aligned}
$$

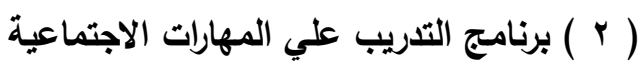

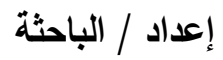

الحاجة للبرنامج

أوضحت كثير من الدراسات والبحوث العلمية أن الأفراد منخفضي جودة الحياة ينقصهم

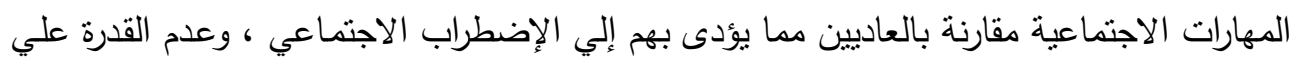

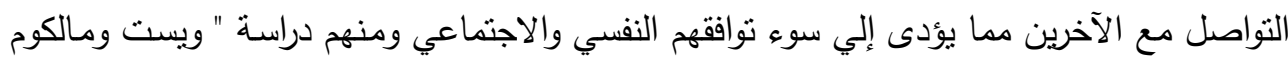

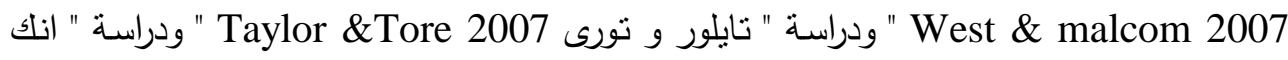
وهارى Ank \& Harrie 2008 " هذا بإلاضـافة إلي أن عدد من الدراسات أكدت علي فاعلية

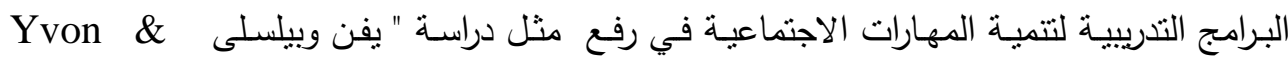
Belisle 2007 " ودراسة " شيلدون وادرينى Sheldon \& Adrienne 2008 " ودراسة " اليسا وهارلان Elissa \& Harlan 2006 " ، وهذه الدراسات أكدت علي أهمية التدريب علي المهارات

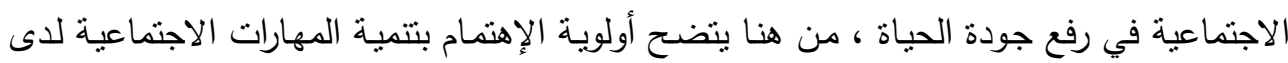
طالبات الجامعة حتى يستطيع هؤلاء تحقيق التوافق الاجتماعي مع المجتمع الذي يعيشون فيه . 
يقوم البرنامج المستخدم في الدراسة " برنامج التدريب علي المهارات الاجتماعية " علي نظرية التعلم الاجتماعي لـ " باندورا ".

بري " باندورا " أن كلاً من البيئات الخارجية والداخلية للفرد تعمل في صورة مترابطة يعتمد بعضها علي البعض الآخر ، ويحدث التعلم كنتيجة للتفاعلات المنبادلة بين كل من البيئتين الداخلية

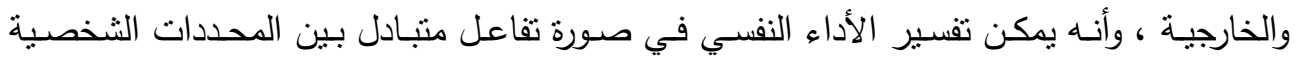

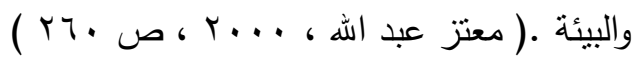

إن التدريب علي المهارات الاجتماعية يقوم علي التعلم بالملاحظة والذي يهدف إلي تعلم

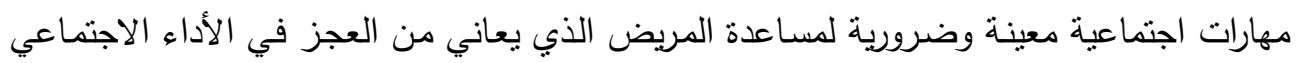
علي القيام بالمهارات الاجتماعية اللازمة في المواقف المخنلفة .

( Adams , 2006, P 23 )

إن عملية التعلم تعطي الفرصة للفرد لتعلم حوانب معرفية ونفسية واجتماعية وثقافية وإتاحة الفرصـة أمام التقويم الذاتي من خـلال تفاعله مـع الهجموعـة أو إحساسـه بردود الأفعال الإيجابيـة والسلبية وإتاحة الفرصة للفرد لمشاركة أفراد المجموعة مشاركة وجدانية والتعاون الجماعي والتفكير بموضوعية .

( Calvert , 2005, P 76 ) 


\section{أهمية البرنامج}

ا - تبرز أهمية البرنامج من الحقيقة التي مؤداهـا أن الوجود الاجتماعي للفرد والذي إذا مـا

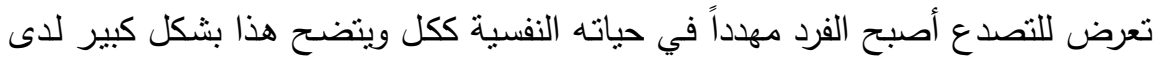
المصسابين باضطراب الثخصية التجنبى ومن ثم لابـد مواجهة هذه المشكلة بالأسلوب

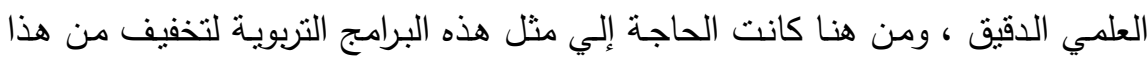
الإضطراب .

r - تبرز أهمية تصميم برنامج التدريب علي المهارات الاجتماعية لطلاب الجامعة حيث أنها

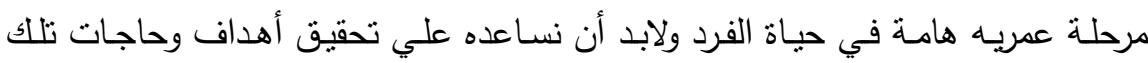

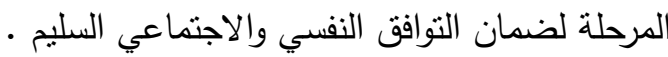

r- يساهم التدريب علي المهارات الاجتماعية في مساعدة الطلاب علي التفاعل مع المواقف الحياتية والتوافق مع المحيطين والأقران وباقي أفراد المجنمع وتمثل المهارات الاجنماعية فئية

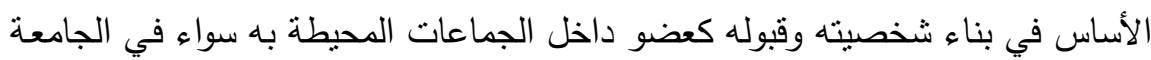

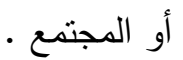

ع - يسـاعد برنـامج التدريب علي المهارات الاجتماعيـة علي تخفيف اضطراب الثخصية التجنبي لدى الطلاب مما يساعدهم في التغلب علي مشكلاتهم وتوجيه تفاعلهم مـع البيئة

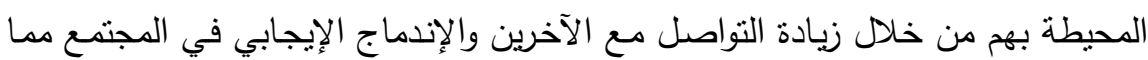

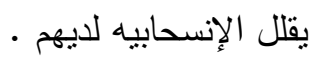
هـ تتمتل أهمية برامج تتمية المهارات الاجتماعية والتدريب عليها كإجراء علاجي يهدف إلي

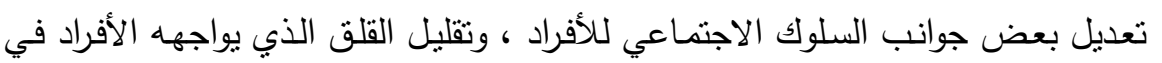

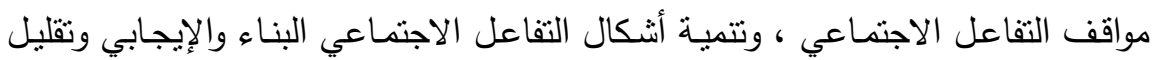

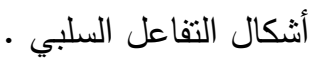

التخطيط العام للبرنامج إنتملت عملية التخطيط العام لبرنامج نتمية المهارات الاجتماعية عدة خطوات نوجزها فيما

( أ ) الفئة التي وضع من أجلها البرنامج : البرنامج موجة طبقاً للهدف العام لتطبيقه علي طالبات مرحلة الجامعة ممن يحصلن علي درجات منخفضة علي مقياس جودة الحياة .

( ب ) الهـف مـن البرنـامج : يهدف البرنامج إلي تتمية المهارات الاجتماعية لدى طالبات كلية التربية بجامعة الباحة والتي بدورها ترفع من جودة الحياة لديهن وهذه المهارات متمتلة في التدريب

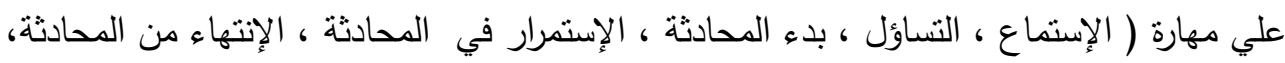

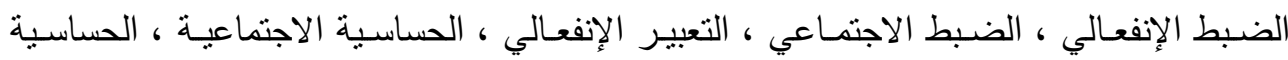
الإنفعالية ، تكوين أصدقاء ، التعبير عن الذات ، التعبير عن المشاعر السلبية ، تحمل المسئولية ). 
( ) المدي الزمني للبرنامج وعدد الجلسات : بناءاً علي طبيعة أهداف البرنامج ، وظروف العينة

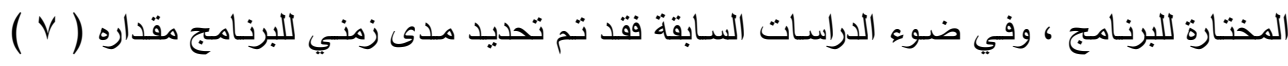

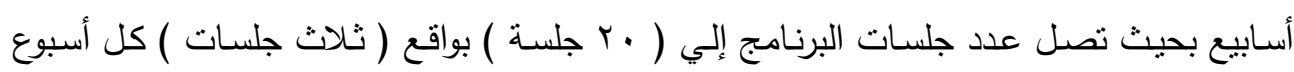
ومدة كل جلسة ( 0 ـ - . . دقيقة ).

( د ) تقييم البرنامج : إن التقييم عملية شاملة ومستمره تهدف إلي تقرير ما نم إنجازه من أهداف قد

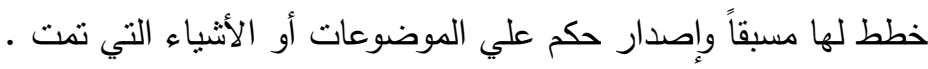
إن تقييم البرنامج يتم من خلال ما يلي :1- التقييم البعدي : من خلال الإطلاع علي نتائج تطبيق مقياس جودة الحياة علي الطالبات بعد

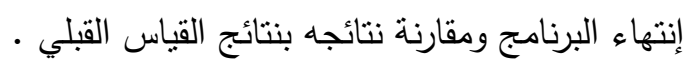
r- التقييم التتبعي : ويتم ذلك بعد شهرين من التقييم البعدي بنطبيق مقياس جودة الحياة علي

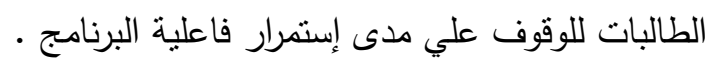

\section{الإسلوب الإرشادي المستخدم في تنفيذ البرنامج وطريقة تطبيقة}

تقوم الباحثة بإنباع أسلوب الإرشاد الجماعي لأن الإرشاد الجماعي عبارة عن إرشاد عدد من

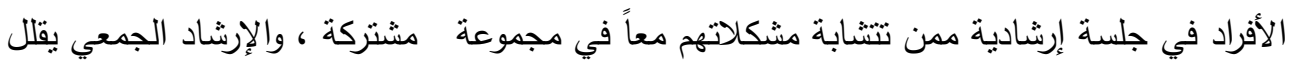

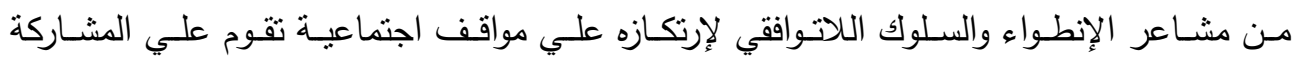
الوجدانيـة والتعـاون المشترك مـن خـلال تفاعل أفراد المجموعـة الذني يعطى لإكتســاب المهـارات الاجتماعية .

نتائج الدراسة نتائج الفرض الأول للاراسة : ينص الفرض الأول على :

توجد فروق ذات دلالة إحصائية في منغير اضطراب الثخصية التجنبي بين منوسطي رتب درجـات طـلاب المجموعـة التجريبيـة في القياسين القبلي والبعدي علي مقيـاس جودة الحيـاة

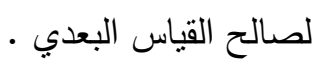

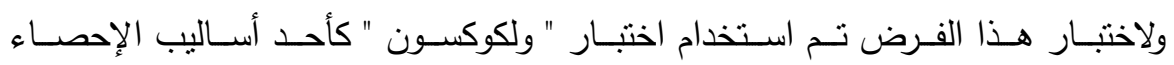
اللابارامترى نظراً لصغر حجم العينة لقياس دلالة الفروق للعينات المرنبطة ــ والجدول التالي يوضح النتائج التي توصلت إليها الباحثة : 
جدول (

معامل ولكوكسون وقيمة " Z" لدلالة الفروق بين متوسطي رثب طلاب المجموعة

التجريبية في القياسين القبلي والبعدي على مقياس جودة الحياة

\begin{tabular}{|c|c|c|c|c|c|c|c|c|c|}
\hline |القياس & ن ن & المتوسط & الالنحراف & منوسط الرتب & الرتب & الرتوسط & الرتب الموجبة & قيمة & مستوى الدلالة \\
\hline قبلي & 1. & $1 \leqslant 9 . r$. & 7.70 & & & & & & \\
\hline | بعدي & 1. & $r r \cdot . q$ & $1 Y .07$ & & & & & & \\
\hline
\end{tabular}

يتضـح من الجدول السابق وجود فروق دالة إحصائياً بين منوسطي رتب درجات طلاب

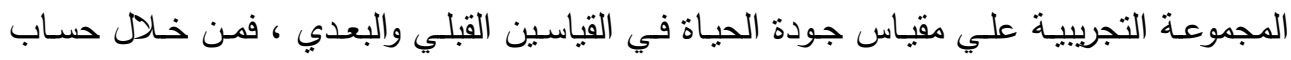
مجموع الرتب الموجبة والأقل تكراراً وجد أنها مساوية ( صفر ) وبالكثف عن دلألتها فئها الإحصائية

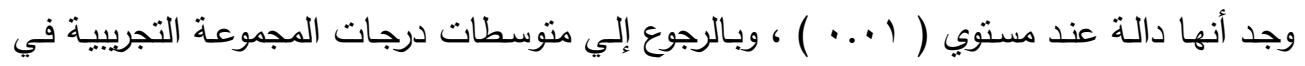

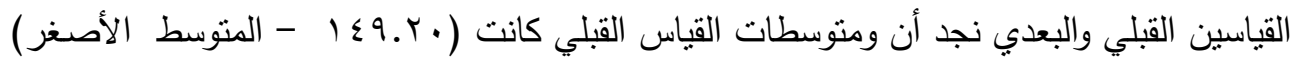

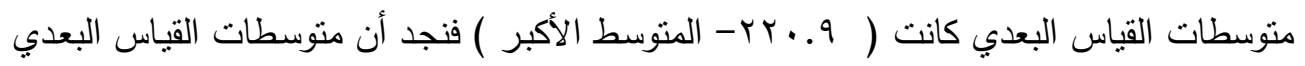

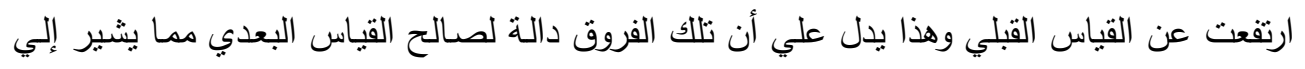

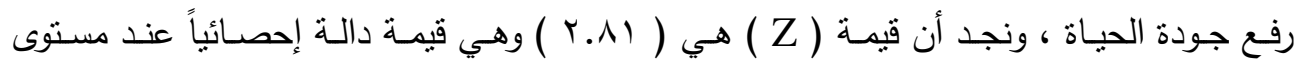
( (1 . ) ومما سبق يتم قبول الفرض الموجه ، وهذا يؤكد على فعالية برنامج التدريب علي المهارات

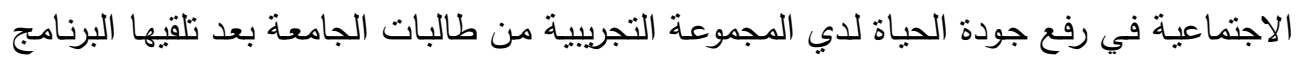
العلاجي الاجم

\section{نتائج الفرض الثاني للاراسة : ينص الفرض الثانى على :}

توجد فروق ذات دلالة إحصائية بين متوسطي رتب درجات طلاب المجموعة التجريبية

والمجموعة الضابطة في القياس البعدي علي مقياس جودة الحياة لصالح المجموعة التجريبية ـ ولاختبار هذا الفرض تم استخدام اختبار " مان ويتتى " لقياس دلالة الفروق للعينات غير المرتبطة ( المستقلة ) ـ والجدول التالي يوضح النتائج التي توصلت إليها الباحثة : 


\section{جدول (0)}

معامل مان وينتى وقيمة " z " لدلالة الفروق بين منتسطي رثب طلاب المجموعة التجريبية

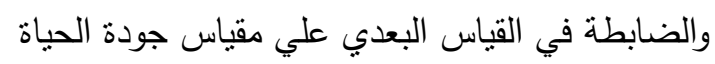

\begin{tabular}{|c|c|c|c|c|c|c|c|c|}
\hline المجموعات & ن ن & المتوسط & الانحراف & متوسط & الرتب & معامل مان & $\begin{array}{l}\text { قيمة } \\
\text { ( Z ) }\end{array}$ & الدلالة \\
\hline التجريبية & 1. & Y) $9 . \varepsilon$. & 1.90 & 10.5. & $10 \leqslant$ & \multirow{2}{*}{$r$} & \multirow{2}{*}{$r .00$} & \multirow{2}{*}{$\ldots$} \\
\hline الضابطة & 1. & $19 \varepsilon .4$ & 7.70 & $0 . \Lambda$. & $0 \wedge$ & & & \\
\hline
\end{tabular}

يتضح من الجدول السابق وجود فروق دالة إحصائياً بين منوسطي رتب درجات طلاب المجموعة التجريبية والمجموعة الضابطة علي مقياس جودة الحياة في القياس البعدي ، فمن خلال حساب معامل " مان ويتتي " وجد أنه يساوي ( ب ) وبالكثف عن دلالته الإحصائية وجد أنه دال

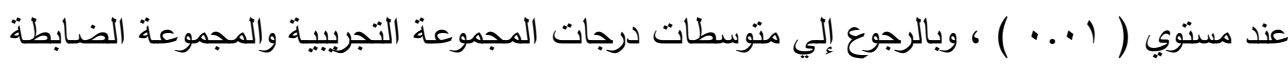

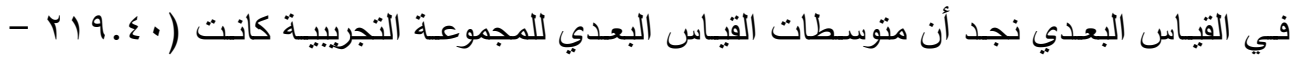

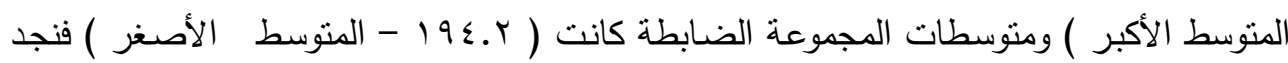

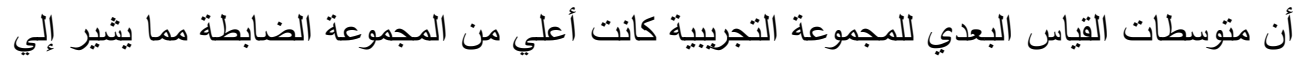

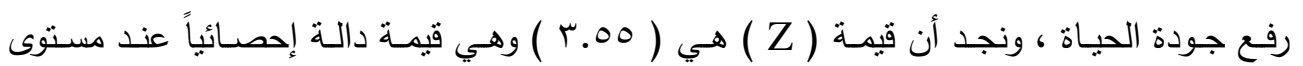

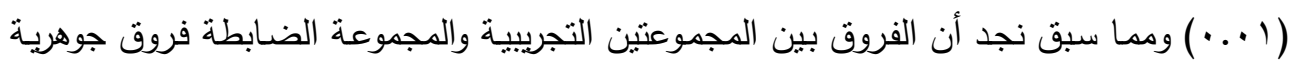

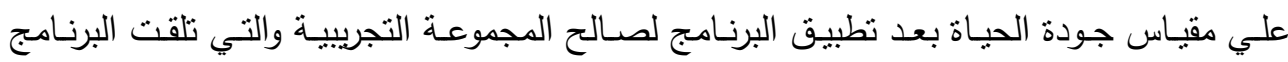
العلاجي مها يشير إلي التأثير الإيجابي للبرنامج علي المجموعة التجريبية من طالبات الجامعة

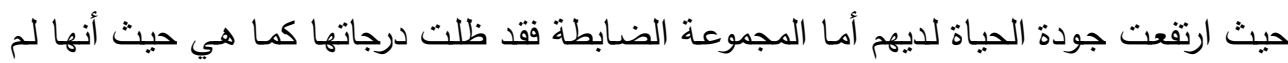

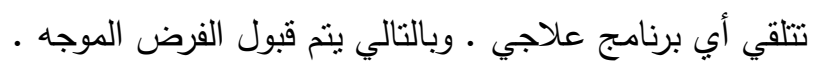
نتائج الفرض الثالث للاراسة

$$
\text { ينص الفرض الثالث على : }
$$

لا توجد فروق ذات دلالة إحصائية بين متوسطي رتب درجات طلاب المجموعة التجريبية

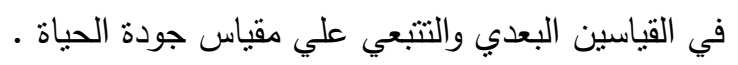

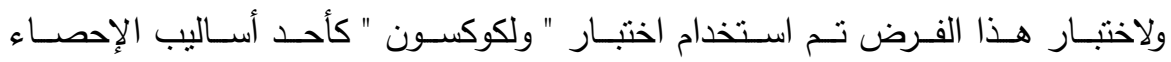

اللابارامترى نظراً لصغر حجم العينة لقياس دلالة الفروق للعينات المرنبطة ــ والجدول التالي يوضح النتائج التي توصلت إليها الباحثة : 


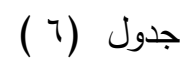

معامل ولكوكسون وقيمة " Z" لدلالة الفروق بين متوسطي رثب طلاب المجموعة

التجريبية في القياسين البعدي والتتبعي على مقياس جودة الحياة

\begin{tabular}{|c|c|c|c|c|c|c|c|c|c|}
\hline القياس & ن & المتوسط & الالنحراف & الرتوسط & الرجموع & الرتوسط & الرجب الرجبة & قيمة & |الدلالة \\
\hline بعدي & 1. & Y) $9 . \varepsilon$. & $1 . .90$ & & & & & & \\
\hline تتبعي & 1. & YYY.A & $1 . .91$ & & & & & & \\
\hline
\end{tabular}

يتضـح من الجدول السـابق عدم وجود فروق دالـة إحصـائياً بين منوسطي رتب درجات

طلاب المجموعة التجريبية علي مقياس جودة الحياة في القياسين البعدي والتتبعي ، فمن خـلال

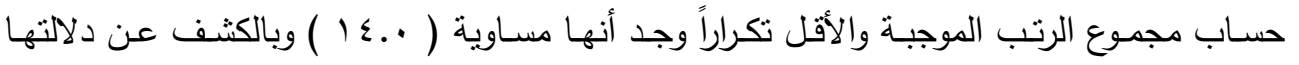
الإحصائية وجد أنها غير دالة مما يدل علي إستمرار التحسن بالنسبة إلي لأفراد المجموعة التجريبية

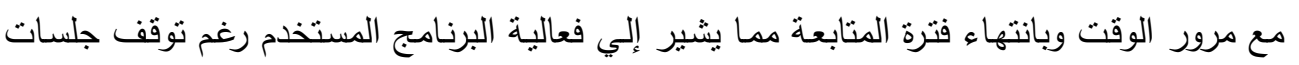

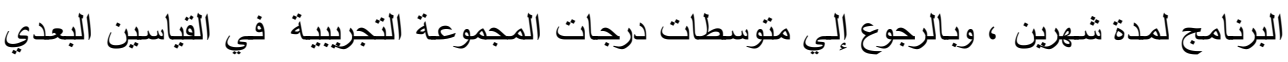

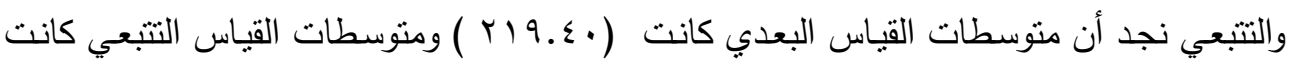
(Y.^.^)

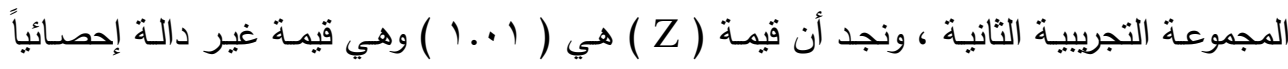

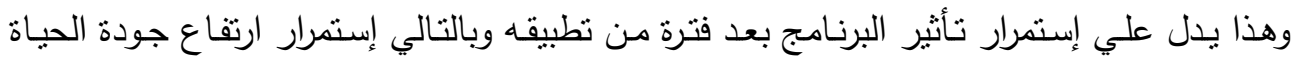

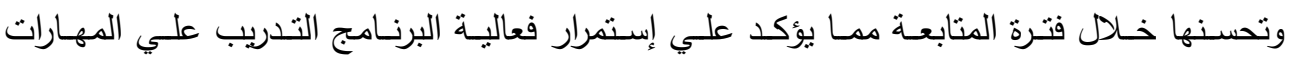

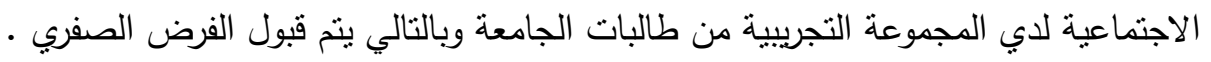
ومما سبق ستضح لنا اهية التدريب علي المهارات الاجتماعية في رفع جودة الحياة وهذا

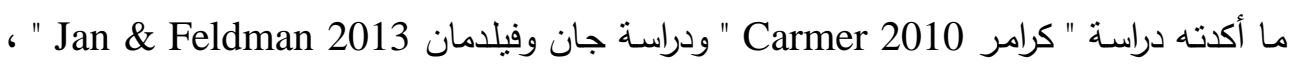
ومن هنـا تكمن أهميـة إكساب الأفراد منخفضي جودة الحياة وتدريبهم علي المهارات الاجتماعية

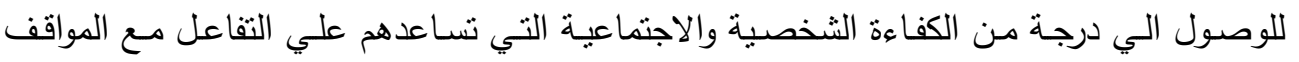

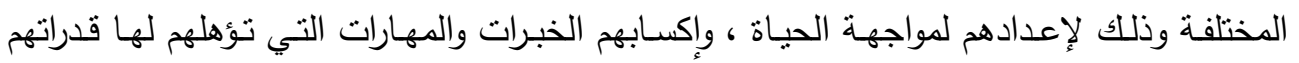

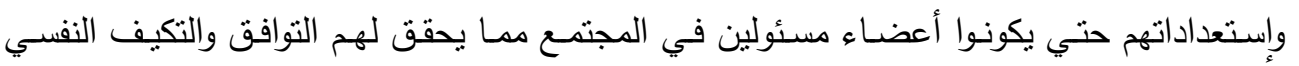

والاجتماعي وهذا ما أكدته دراسة " لينون Lenon 2011 " ودراسة ارنولد 2014 Arnold " . 


\section{توصيات الدراسة}

في ضوء نتائج الدراسة الحالية تتقدم الباحثة بالتوصيات الآتية:

ا- إدخال مفهوم جودة الحياة في بعض مقررات علم النفس بالجامعات، لأن هذا يساعد كثيراً

في إدراك الطلبة لمعايير جودة الحياة.

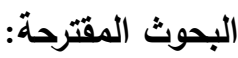

ا - دراسة فاعلية العلاج المعرفي السلوكي في رفع جودة الحياة لدي طالبات المرحلة الثانوية .

r- دراسة العلاقة بين جودة الحياة وبعض المتغيرات النفسية الأخرى، منل الأمن النفسي ، دافعية الانجاز ، والقلق، ومفهوم الذات، والضغوط النفية ولنفية. 
أبو هاشم، السيد محمد (ع . . r) : سيكولوجية المهارات ، القاهرة ، مكتبة زهراءالشرق •

جابر ، عبدالحميد جابر و كفافي ، علاءالدين (990 1): معجم علم النفس والطب النفسي ، الجزء السابع ، القاهرة ، دار النهضة العربية .

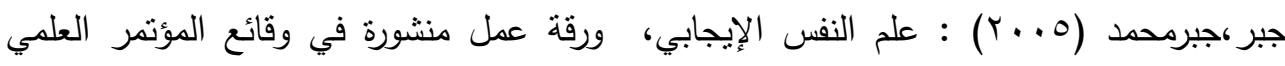

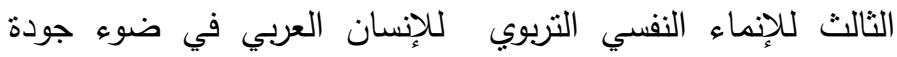

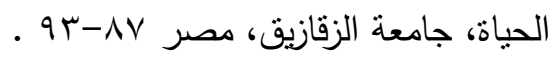

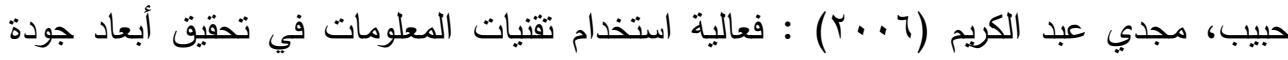

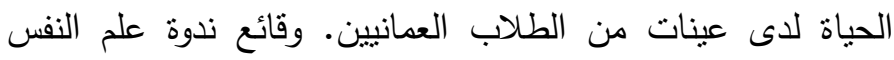
وجودة الحياة مدى إحساس طلبة كلية التربية بالرستاق بجودة الحياة وعلاقة ذلك ببعض المتغيرات. وقائع ندوة علم النفس وجودة الحياة

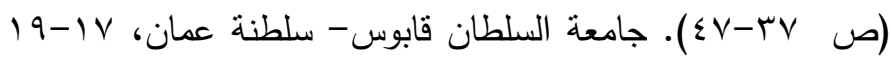

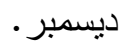

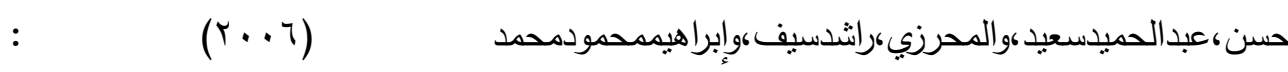
جودةالحياةوعلاقتهابالضغوطالنفسية واستراتيجياتمقاومتهالدطلبةجامعةالسلطانقابوس.

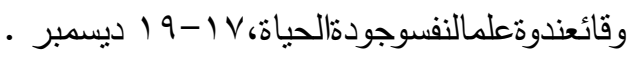

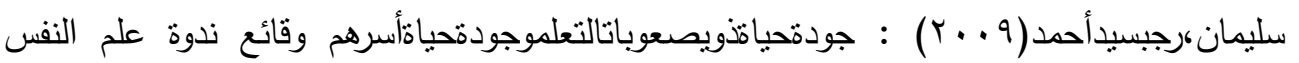
وجودة الحياة .

الثهاوي، شيماء السعيد عبيد (د.ت) : مقياس جودة الحباة ، غير منشور صالح، ناهد ( . . . م) : مؤشرات جودة الحياة نظرة عامة على المفهوم والمدخل. المجلة الاجتماعية

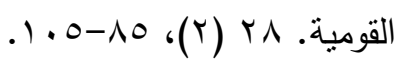

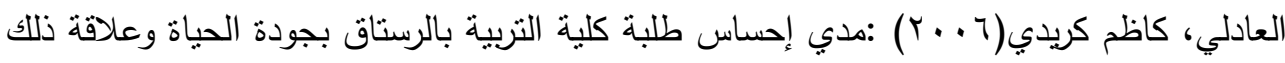

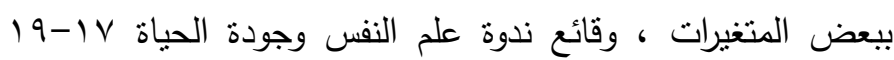

$$
\text { - ديسمبر - }
$$

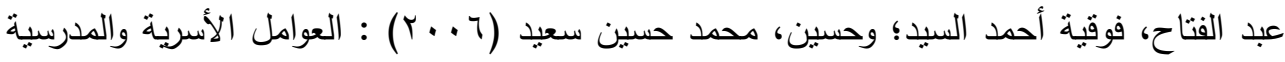
والمجتمعية المنبئة بجودة الحياة لدى الأطفال ذوي صعوبات التعلم بمحافظة بني سويف. وقائع المؤتمر العلمي الرابع: دور الأسرة ومؤسسات المجتمع المدني في لاكتثاف ورعاية ذوي الحاجات 


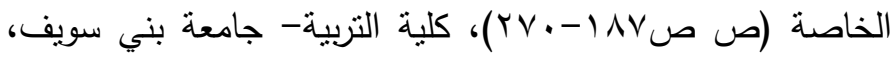

$$
\begin{aligned}
& \text { r- }
\end{aligned}
$$

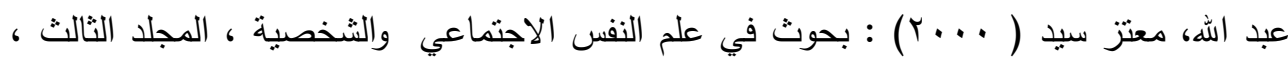

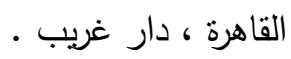

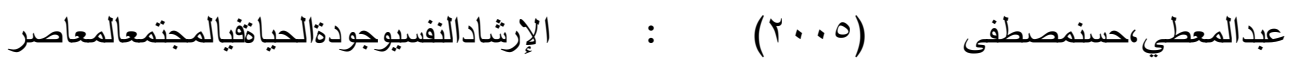
ورقةعملمنشورةفيو قائعالمؤتمرالعلميالثالتلإنماء النفسي

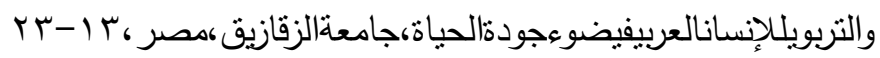

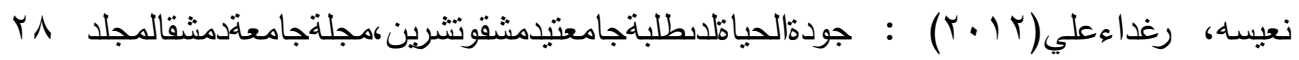
العددالأول،

Adams, H. (2006): Loneliness in late adolescence : A social skills training study , Journal of adolescnce research , (3) , 17-31.

Adkins, G. (2008): Job-related social skills training with female prisiners, Behavior modification ,(56), 95-112.

Ank, E. \& Harrie, S. (2008): Social skills problem in avoidant personality disorders : Social skills training with and without cognitive modification, Princeton : Princeton university press.

Arnold, D. (2014): Comparison of efficacy of social skills training for deficit and nondeficient negative sympotoms in avoidant personality disorder, American journal of psychiatry , 50-87.

Berner, D. \& Fee, M. (2008): Effect of social skills training for student with avoidant personality disorder, International journal of disability, Devlopment and education , 4-32 .

Bullkeley, R. \& Carmer, S. (2010): Social skill training with you adolescents , Journal of youth and adolescents , 19 (5) , 251-263 .

Calvert, D. (2005): Using a cognitive process approach to teach social skills, Education and training in mental retardation, (34), 65-85.

Carmer, D. (2010): Social skills training for avoidant personality disorder girls: Interpersonal skills training, Behavior change, (11) , 224-252 .

Craig A. Jackson (2010): Work-Related Quality of Life, Health Research Consultation Center, Oxford University Press. 
Elissa, D. \& Harlan, S. (2006): Social skills training to reducen avoidant personality disorder in adolescents, New York: Basic Book Inc.

Fabian, K. (2006): Social skills , Englewood Cliffs , NJ : Prentice - Hall .

Felce, D. \& Perry, J. (2007): Quality of life: the scope of the term and its breadth of measurement. In Quality of life for people with disabilities. Models, research and practice. Ed. Roy I Brown. Stanley Thornes.

Ferris, M. (2008): Social skills training program for avoidant personality disorder persons with developmental delays: Generalization and social validity , Bebavior modification , (100) , 46-65.

Hajiran, H., (2006): Toward a Quality of life Theory: Net Domestic Product of Happiness. Social Indicators Research, 75 (1), 31 -43 .

Hazel, B. (2008): Outcome assessment in social skills training with adults , Journal of school psychology , (3), 34-51.

Heinssen, M.\& Liberman, B. (2014): Generlization of the effects of activity therapy and social skills training on the social behavior of avoidant personality disorder patients, Occupational therapy in mental health, (68), 30-54.

Herbert, M. (2008): Clinical child psychology social learning, development behavior, New York, John Wiley \& Sons, chic hester.

Hersen, C. \& Turner, F. (2008): Social skills training to improve alcoholics' vocational interpersonal competency, Journal of counseling psychology , (43), 108-123.

Jan, N. \& Feldman, R. (2013): Social skills training for persons with avoidant personality disorder: An expansion of behavior paradigm, International Journal of Behavioural Consultation , (72), 30-43.

Jonker,C. , Gerritsen.D.L, Bosboom P.R.\&, J.T. Van der Steen J.T. (2004): A Model for Quality of Life Measures.

Katschnig H. (2007): How Useful is the Concept of Quality of Life in Psychiatry? In Quality of Life in Mental Disorders (Eds H. Katschnig, H. Freeman, N. Sartorius), 3-16. Wilev, Chichester.

Lenon, C. (2011): Social skills in adluts with avoidant personality disorder and servers disabilities (mental reardation), Dissertation abstracts international , (65) , 723-743.

Mintz, D. (2008): Structured learning in teaching therapists social skill training : Acquisition, maintenance, and impact on 
client outcome, Journal of counseling psychology , (41) , 26-41.

Reine , E.P. Seligman , Tracy A. Steen \& Christopher, Peterson. (2013): Positive Psychology Progress: Empirical Validation of intervention, U.S.A: Positive Psychology

Sheldon, K. \& Adrienne, U. (2008): Social skills training for patients with avoidant personality disorders, Journal of youth and adolescence , (7), 65-87.

Tauber, D. \& Wallace, U. (2008): Social skills training for avoidant personality disorders individuals at risk for relapse , American journal for psychiatry , 120-135.

Taylor, D. \& Tore, M. (2007): A test of the therapeutic mechanism in social skills training with avoidant personality disorder, Center of research in mental retardation, Indian society, (36) , 233-243.

West, E. \& Malcom, J. (2007): Treatment of avoidant personality disorder by social skills training, Caures ompanies, U.S.A.

Whoqol Group (2005): The World Health Organisation Quality of Life Assessment.

Wilson, W. (2007): Social skill training with adults : Issues in research and practice, Journal of psychosomatic research , (26), 74-89.

Yvon, M.\& Belisle, R. (2007): Social skills training and avoidant personality disorder among adolescents, American journal on mental retardtion , (54), 231-245. 


\title{
Effectiveness of Training Program on Social Skills in Improving Life Quality among a Sample of Female Students of College of Education at Al-Baha University
}

\author{
Prepared by
}

\author{
Assistant Professor/ Fatma Mohammed Ahmed Braik \\ Assistant Professor of Curricula \& Teaching Methods \\ College of Education - Al-Baha University \\ Deputy of Students' Affairs Deanship - Al-Baha University
}

\section{Summary}

The present study aimed to identify the effectiveness of training program on social skills in improving life quality among a sample of female students of college of education at AlBaha University. The study sample included (20) students of college of education divided into two groups: experimental and control groups 10 students each of female students of college of education at Al-Baha University. The researcher adopted the following tools:

1. Life Quality Scale, prepared by ShaimaaAlsaeedAlshehawi

2. Training Program on Social Skills in Improving Life Quality, developed by the researcher.

The study reached the following findings:

1. There are statistically significant differences in life quality variable between the scores means of experimental group in the pre-test and post-test on life quality scale for the favor of post-test.

2. There are statistically significant differences between the scores means of experimental group and the control group in the post test on life quality scale for the favor of the experimental group.

3. There are no statistically significant differences between the scores means of control group in the pre-test and post-test on life quality scale 